\title{
Entre el libre comercio y el proteccionismo. Impacto de los obstáculos sobre la equidad en el comercio en el marco de la Agenda 2030
}

\author{
Between free trade and protectionism. Impact of barriers on equity \\ in trade, within the framework of the 2030 Agenda
}

\section{Gerardo COPPELLi ORTIZ}

Profesor de Derecho Internacional Económico

Universidad Central de Chile, Chile

gerardo.coppelli@ucentral.cl

Resumen: El objeto del presente trabajo, es analizar el estado actual del libre comercio, la imposición de barreras, tanto arancelarias como no arancelarias, y su incidencia para la equidad del comercio internacional. Dicho análisis aborda de manera particular la evolución del libre comercio y las distintas restricciones y obstáculos que los países han impuesto, procurando por una parte, la protección de su industria nacional, la defensa de sus propios intereses y por otra parte, la búsqueda de la apertura comercial y la facilitación del comercio a través de la liberalización generalizada de barreras. Junto a lo anterior, se hace una revisión de los objetivos planteados por la comunidad internacional para los próximos años, tomando como referencia el horizonte del año 2030, en el marco de los Objetivos de Desarrollo Sostenible.

Palabras clave: Obstáculos al comercio; proteccionismo; equidad en el comercio; medidas no arancelarias; ODS 2030.

\begin{abstract}
The objective of the present article, is to analyze the current situation of free trade, the imposition of barriers, both tariff and non-tariff, and its incidence for the equity of international trade. This analysis deals in particular with the evolution of free trade and the different restrictions and obstacles that countries have imposed, seeking, on the one hand, the protection of their national industry, the defense of their own interests and, on the other hand, the search for commercial opening and trade facilitation through the general liberalization of barriers. Together with the above, a review is made of the objectives set by the international community for the coming years, taking as reference the horizon of 2030 , within the framework of the Sustainable Development Goals.
\end{abstract}

Keywords: Barriers to trade; protectionism; equity on trade; non-tariff measures; GOALS 2030.

Sumario: I. CONSIDERACIONES PRELIMINARES. II. EL DESARROLLO CONTEMPORÁNEO DEL LIBRE COMERCIO Y LA BÚSQUEDA HISTÓRICA DE LA EQUIDAD EN EL COMERCIO. III. EL PROTECCIONISMO FRENTE AL LIBRE COMERCIO: LA DEFENSA DE INTERESES INTERNOS. IV. DE LAS BARRERAS, OBSTÁCULOS Y RESTRICCIONES. 1. El arancel, concepto Y efectos. 2. Las barreras no arancelarias. A. Clasificación de las BNA. B. Otras BNA. a) Los contingentes o cuotas de importación. b) Las subvenciones. c) El dumping. d) Boicot y bloqueo. V. RESULTADOS DE LA POLÍTICA DE LIBRE COMERCIO EN LAS PERSONAS. LOS OBJETIVOS DE DESARROLLO SOSTENIBLE (ODS) DE LA AGENDA 2030. 1. La Ronda del Milenio de la OMC. 2. Los ODS en el horizonte de 2030. VI. CONSIDERACIONES FINALES. 


\section{CONSIDERACIONES PRELIMINARES}

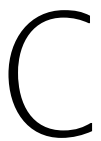

uando hablamos de libre comercio, nos referimos a una forma exitosa, ágil, dinámica y global, de llevar la producción de bienes y la prestación de servicios, desde y hacia distintas partes del mundo, hoy casi sin limitaciones, de una manera tan fluida, que hasta hace unas cuantas décadas atrás habría sido imposible concebir.

De esta afirmación, seguramente no se derivarán profundas discusiones en cuanto a la forma técnica como se ha desarrollado, la globalidad de los acuerdos suscritos y la capacidad de las instituciones que los administran, todos ellos, argumentos que han permitido cimentar una estructura comercial internacional de diametral envergadura ${ }^{1}$.

Quizás ya no tan mayoritaria, será la opinión en cuanto al fin, destino y reparto de los frutos del libre comercio, las desigualdades generadas en el tratamiento y resultados entre las distintas economías, el beneficio real, o bien, resumiéndolo en un único concepto, lo que podríamos llamar como resultado subjetivo, la «equidad del comercio». Junto con esta inquietud, también se plantea la idea de que si bien el libre comercio se ha ido abriendo paso sistemáticamente, derribando una a una las barreras que los distintos países o bloques económicos, justa o injustamente, han ido imponiendo, la implantación de barreras, obstáculos y restricciones al comercio internacional que lo dificultan de forma artificiosa, han perseguido proteger en muchos casos, de forma desleal, la producción nacional frente al comercio importado.

1 Según un reciente informe de la OMC, durante 30 años, el comercio internacional de mercancías, tuvo un crecimiento medio anual de 7,3\%, lo que se traduce en que, de 2,03 billones de dólares de los Estados Unidos (US\$) en el año 1980, pasó a US\$ 18,26 billones en 2011. En cuanto a los servicios el crecimiento fue aún mayor, pasando de US\$ 367.000 millones en 1980 a US\$ 4,17 billones en 2011, es decir, un 8,2\% de promedio anual. Por tanto, concluye el informe, el comercio mundial de mercancías se cuadruplicó entre los años 1980 y 2011. Cfr. OMC. Informe sobre el Comercio Mundial 2013. Factores que determinan el futuro del comercio. Disponible en https://www.wto.org/spanish/res_s/booksp_s/world_trade_report13_s.pdf.

En cualquier caso, resulta pertinente aclarar que en los últimos años, y producto de un estancamiento generalizado del comercio internacional y de un debilitamiento en la economía mundial, el comercio de mercancías se redujo, desde un 2,6\% en el año 2015 , a un $1,3 \%$ en el año 2016. Cfr. OMC. Examen estadístico del Comercio Mundial 2017. Disponible en https://www.wto. org/spanish/res_s/statis_s/wts2017_s/wts2017_s.pdf

No obstante lo señalado precedentemente, entendemos que estos datos coyunturales no distorsionan la realidad a largo plazo, en la que se vislumbra claramente el positivo desarrollo, permanente y sostenido, tanto del comercio de mercancías como de servicios. 
Es así como sabemos que, no obstante, las reconocidas ventajas que plantea el libre comercio, los países mantienen, en mayor o menor medida, la imposición de restricciones al comercio que limitan, inhiben o directamente excluyen, las relaciones comerciales internacionales. En este sentido, se plantea que bajo argumentos económicos y extraeconómicos, como lo son, la seguridad nacional, la salud, el medio ambiente, y otros incluso más complejos y elaborados, como la defensa de la producción y del empleo del país, la defensa de intereses empresariales, normas de calidad de productos, protección de los consumidores, etc. entre otros, los países imponen restricciones al comercio de mercancías y servicios, argumentando que un mercado libre obliga a que se produzcan ajustes ${ }^{2}$. Sin perjuicio de lo anterior, el establecimiento de lo que veremos más adelante, aranceles y otras barreras al comercio, son considerados una vía válida para contrarrestar ajustes y distorsiones al comercio internacional.

Ahora bien, a pesar de la existencia de acuerdos internacionales que regulan la materia, y reconociendo, por otra parte, la capacidad de los Estados para definir de manera individual su política comercial, existen innumerables barreras y obstáculos en virtud de los cuales los Estados pueden restringir o ampliar dicha política. Al respecto, siendo tal la diversidad de restricciones capaces de impedir o dificultar las transacciones internacionales, resulta casi imposible poder elaborar una clasificación absoluta.

Desde la tradicional imposición de aranceles a la importación de mercaderías, pasando por otra clase de barreras de orden técnico y de protección de la industria nacional, o como lo que hemos podido apreciar recientemente, decisiones gubernamentales, que sin un mayor fundamento económico que el sólo «aislacionismo» ${ }^{3}$, se ha ido abriendo paso una especie de disyuntiva económica, que nos plantea dos tipos de cuestiones íntimamente relacionadas.

2 Fernández, J.C., Sistema de derecho económico internacional, Pamplona, Aranzadi, 2010, p. 159.

3 No es casual, que el concepto de «aislacionismo» comercial actual, lo veamos principalmente reflejado en los postulados económicos del Presidente Donald Trump, en Estados Unidos, pues dicho concepto nace precisamente en una tradicional e histórica postura del país americano, en virtud de la cual, ha procurado no involucrarse en aquellos asuntos o negocios que no le atañen directamente. Es cierto que en las últimas décadas dicha postura ha sido soslayada con importantes intervenciones, tanto políticas, como económicas a nivel global, pero con las deliberadas renuncias a participar, por ejemplo, en el Acuerdo Transpacífico de Cooperación Económica (conocido por sus siglas en inglés TPP), que representaba, con la incorporación de Estados Unidos, el principal acuerdo económico y comercial global; su revisión del Acuerdo NAFTA entre Canadá, México y el propio Estados Unidos, entre otros, nos retrotrae a la postura aislacionista tradicional norteamericana de los siglos XVIII, XIX y la primera parte del siglo XX. 
Por una parte, el afán de ciertos Estados, de proteger su economía, a través de medidas y políticas internas, con la idea de salvaguardar su propia industria, su mano de obra e inversión, entendiendo bajo esa postura, una efectiva equidad de comercio, y por la otra, la convicción de que la verdadera equidad proviene de dar a la población la facilidad de acceso a bienes y servicios, que sin la intervención de una política comercial aperturista, sería muy difícil de cumplir.

Sin perjuicio de dicha complejidad, y más allá de las distintas barreras y obstáculos que podamos encontrar, es importante reconocer que la Organización Mundial del Comercio (OMC) permite a los países importadores adoptar medidas de protección comercial, siempre que estas medidas tengan como objetivo neutralizar determinadas prácticas comerciales desleales en el comercio internacional por parte de otros Estados. No obstante aquello, y para que las medidas se mantengan en la esfera de la protección comercial y no del «proteccionismo», la OMC ha establecido condiciones y procedimientos a los que deben adecuarse sus miembros ${ }^{4}$, ya sea en materia de mercancías, como de servicios, así como también en inversiones y propiedad intelectual ${ }^{5}$.

Si bien es posible suponer que los países industrializados son los productores naturales de manufacturas, es obvio pensar que estos países sean también, por este efecto, los principales importadores de materias primas y por tanto, los principales exportadores de productos manufacturados. Al contrario, serán las exportaciones de productos básicos las que provengan de países con menor nivel de desarrollo. Pero en alguna medida, atribuible a la función integradora del sistema de comercio internacional y fundamentalmente al rol que en esta materia ha cumplido la OMC, este planteamiento ya no es del todo tan indiscutible. Al día de hoy, aproximadamente el $40 \%$ de las exportaciones de los países en vías de desarrollo son de bienes manufacturados, y al contrario, existen países industrializados con importantes niveles de exportación de productos primarios, en especial productos agrícolas ${ }^{6}$. En cualquier caso,

4 López-Jurado, C.; Martín, P., «La regulación material del comercio internacional», en L. Hinojosa y J. Roldán (coords.), Derecho internacional económico, Madrid, Marcial Pons, 2010, pp. 108-109.

5 Al respecto, Vid. https://www.wto.org/spanish/tratop_s/tratop_s.htm

$6 \mathrm{Al}$ respecto, sin dejar pasar la inagotable discusión respecto de la real dimensión comercial que tiene la actividad agrícola en países industrializados, dada la fuerte crítica llevada adelante por países en desarrollo, a propósito de las importantes subvenciones que reciben los productores por parte de sus gobiernos, para el «mantenimiento artificial» de dicha actividad. Fernández sostiene al respecto, que gran parte de los países en vías de desarrollo señalan que los principios emanados del GATT, y actualmente de la OMC, han sido un constante obstáculo a sus exporta- 
y en términos brutos, los países industrializados siguen siendo los grandes exportadores a nivel mundial, concentrando además, más de la mitad de los intercambios totales ${ }^{7}$.

Asumiendo la realidad de un país cualquiera, el comercio internacional, bajo una mirada de política comercial aperturista, representa, sin lugar a dudas, una serie de ventajas, acceso a materias primas extraídas o producidas en otros mercados, productos elaborados a costos menores que los de su propia producción, acceso a mano de obra, sea ésta calificada o más barata, etc. La disyuntiva se genera una vez que analizamos si estas y otras ventajas benefician a todos los países de la misma forma, o al menos en un mismo rango. Si consideramos que la exportación de manufacturas es mayor que la de productos primarios, y si a su vez reconocemos que los productos manufacturados provienen esencialmente de economías industrializadas estamos, por tanto, en presencia de un beneficio claramente mayor de estas economías sobre las primarias. Y además teniendo en cuenta la alta volatilidad de los precios de productos primarios y la imposibilidad de poder determinarlos por parte de estas mismas economías, así como la incidencia del clima, las variables políticas, etc., factores que los convierten en una mercancía altamente vulnerable y por tanto, como consecuencia de ello, definen al país productor como una economía frágil ${ }^{8}$.

De cualquier manera, y cualquiera sea la forma bajo la cual analizamos las variables del libre comercio y su fluidez y/o protección, nos encontramos con la disyuntiva de su objetivo final, ciertamente no discutiendo la validez de las mismas. Pareciera ser, que en todos los casos, un comercio internacional tendente a la equidad en el comercio, con un fin social y de ayuda a la superación de la pobreza, resulta ser un fin lícito y perseguido. El problema se plantea cuando bajo el modelo comercial actualmente imperante, estos objetivos son

ciones de textiles y de productos agrícolas y que las nuevas exigencias acerca de la situación de los trabajadores o en materia de medio ambiente no son más que medidas tendentes a frenar su productividad. Además, agrega el autor, que a ello se une una «cierta obsesión generalizadora» que extiende las supuestas bondades y ventajas del sistema de comercio internacional a todos los países con independencia de su situación concreta. Vid. FernándEZ, J.C., Sistema de Derecho económico internacional, op. cit., p. 62.

7 Requeijo, J., Economía mundial, $4^{\circ}$ ed., Madrid, McGraw-Hill, 2012, p. 2. En el año 2016, el $53 \%$ del total del comercio mundial de mercancías, lo concentraron las 10 principales economías mundiales, en tanto que, la suma de todos los países en desarrollo (cerca de 110 países) representó sólo un 41\%. Cfr. https://www.wto.org/spanish/thewto_s/whatis_s/tif_s/dev1_s.htm; y Cfr. OMC. Examen estadístico del Comercio Mundial 2017, op. cit., p. 16.

8 Rodríguez, M.J., «Relaciones comerciales internacionales», en M. De Paz (dir.), Economía mundial, 2ª ed., Madrid, Pirámide, 1998, p. 172. 
o no realmente un fin en sí mismos, son un efecto colateral o son secundarios, y por tanto, una mera justificación a las medidas proteccionistas o al proteccionismo propiamente dicho9 .

Sin el afán de anticipar conclusiones, podemos entender a priori, que el comercio internacional puede ser una importante vía, en potencia, para la superación y reducción de la pobreza, para la creación de empleos, para promover la competencia, incrementar la productividad y la promoción de nuevas ideas. En cualquier caso, el resultado esperado del libre comercio tendente a estos objetivos no es automático: el confiar en que la liberalización del comercio trae como resultado inherente la superación de la pobreza sería un error ${ }^{10}$, no creerlo como una vía posible para ello, también lo sería. Entonces, ¿en qué punto nos encontramos?, ¿el libre comercio ha logrado ser un agente determinante en la reducción de los índices de pobreza y equidad social? ¿la imposición de barreras y obstáculos al comercio obedecen a este criterio o más bien siguen fundamentos estrictamente económicos, de mejor venta y mayor ganancia?

De cualquier forma, cabe preguntarse si podemos entender como destinatario final de los principios que rigen el comercio internacional a las personas, o más bien, ¿el comercio libre y fluido, más competitivo, previsible y transparente son en sí mismos fines encaminados al bienestar del Estado como tal?; ¿las personas somos un efecto colateral del libre comercio, o somos el verdadero fin en cuanto promoción de equidad y la búsqueda del mayor equilibrio y bienestar posible? Si el cumplimiento de los objetivos propuestos por Naciones Unidas para el año 2015 no ha sido suficiente, ¿cómo vamos encaminados al cumplimiento de los «Objetivos de Desarrollo Sostenible» en la perspectiva del año 2030? ${ }^{11}$

9 Como muestra del retroceso en el comercio mundial, y la fragilidad que muestran las economías en desarrollo, confrontando con la información planteada en la nota 10 previa, hasta el término del año 2013, el 44\% de las exportaciones mundiales de mercancías procedió de economías en desarrollo, es decir, un 3\% mayor que el porcentaje actual, 3\% perdido en sólo tres años, mientras que para el mismo periodo, el $52 \%$ de las exportaciones lo hizo de economías desarrolladas, es decir, un recupero de un $1 \%$ en los últimos tres años. A su vez, sobre dos tercios de las exportaciones de las economías desarrolladas correspondió a productos manufacturados, al contrario, sobre dos tercios de las exportaciones de economías en desarrollo correspondió a productos primarios. Cfr. OMC. Estadísticas del Comercio Internacional 2014, p. 12 y 78. Disponible en https:// www.wto.org/spanish/res_s/statis_s/its2014_s/its2014_s.pdf

10 Goldin, I.; ReInerT, K., Globalización para el desarrollo, traducción a cargo de Patricia Durán, Bogotá, Planeta y Banco Mundial, 2007, p. 83.

11 Estos objetivos en conjunto, tanto «Los Objetivos de Desarrollo del Milenio» (ODM), como «Los Objetivos de Desarrollo Sostenibles» (ODS), se analizarán con mayor detalle en el apartado $\mathrm{V}$ del presente trabajo. 


\section{EL DESARROLLO CONTEMPORÁNEO DEL LIBRE COMERCIO Y LA BÚSQUEDA HISTÓRICA DE LA EQUIDAD EN EL COMERCIO}

En la búsqueda de respuestas en cuanto al fin del libre comercio, su anhelada equidad, la función del Estado y la observancia de las personas frente a ello, podemos apreciar distintas posturas, conductas y enfoques a lo largo de la historia. Si bien, la equidad del comercio pareciera ser un fin por siempre pretendido, la forma a través de la cual se ha buscado su implementación, ha variado en el tiempo. Desde posturas aislacionistas, procurando la protección interna de los factores productivos, fundamentalmente, en inversión y mano de obra, a posturas directamente aperturistas, prescindiendo de la protección de la industria nacional y enfocado a la importación de productos extranjeros, con mejor costo y de más fácil acceso ${ }^{12}$.

Desde mediados del siglo XIX, y a propósito de la caída de los precios del transporte en ese momento ${ }^{13}$, se facilitó el intercambio de grandes mercancías como metales, cereales y textiles, de forma tal que los precios se comenzaron a estandarizar internacionalmente. Pero producto del mismo proceso, dichos bienes también se comenzaron a elaborar en los países importadores, por tanto estos productos importados se convirtieron en competencia directa de la producción nacional ${ }^{14}$. Es así, como por ejemplo, los agricultores europeos se encontraron con la competencia directa de productos agrícolas americanos y asiáticos. En sentido contrario, las textiles asiáticas enfrentaron la dura competencia que le imponía la creciente industria textil europea. Los precios, por tanto, pasaron a estar determinados, más que por la oferta y demanda nacional, por el comercio mundial y los mercados internacionales. En los países en donde se impusieron

12 En relación a las ventajas y desventajas del modelo de comercio internacional imperante en el siglo XIX, Vid. Bastable, C.F., The theory of international trade, $4^{\circ}$ ed., London, MacMillan and Co. Limited, 1903, pp. 13-21.

13 Durante el siglo XIX, el barco a vapor constituía la forma más importante y tecnológica para el transporte de mercancías. Durante la primera mitad del siglo, su uso principal se hacía en ríos, grandes lagos y mares interiores, como el Báltico y el Mediterráneo. Ya con la apertura del Canal de Suez, en 1869, el comercio con Oriente se hizo más fluido y directo. Junto con el avance en la construcción de barcos a vapor surge el ferrocarril. En 1830 la inauguración de la línea férrea Liverpool - Manchester, y a continuación, la construcción allá por 1850, de líneas férreas en Bélgica, Francia y Alemania, contribuyeron a diversificar en gran medida las vías de transporte existentes hasta entonces. Al respecto, Vid. O'Rourke, K.; Williamson, J., Globalización e Historia: la evolución de la economía atlántica en el siglo XIX (traducción a cargo de Montse Ponz), Zaragoza, Prensas Universitarias de Zaragoza, 2006, p. 56-57.

14 Vid. Comín, F., Historia económica mundial, Madrid, Alianza Editorial, 2011, p. 461. 
los grupos proclives al libre comercio, se mantuvieron políticas librecambistas. $\mathrm{Al}$ contrario, hubo otros países con preeminencia del establecimiento de tarifas arancelarias, destinadas esencialmente a defender la industria nacional ${ }^{15}$.

En el periodo entre guerras, una fuerte tendencia proteccionista se impuso entre las grandes potencias. Mientras Estados Unidos y Gran Bretaña incrementaban drásticamente sus aranceles para la protección de las industrias básicas, Francia y Alemania lo hacían para la protección de su actividad agrícola. Fue así como en el año 1921, Estados Unidos implementó la ley Fordney-Mac Cumber, que supuso el incremento de los aranceles para productos primarios y derivados de industrias básicas, que duró esencialmente hasta el año 1930, producto de la Gran Depresión del año 1929. En Gran Bretaña, en el mismo año 1921, se aplicó la ley denominada Safeguarding Industries Act., que más que aranceles, imponía salvaguardias a ciertos productos claves de la industria británica, por el período de cinco años.

Más tarde, consciente de los efectos adversos que generaba la contracción comercial internacional generalizada en la cual se encontraba la economía mundial, Estados Unidos promocionó la idea de liberalizar los intercambios comerciales. Fue así como, a continuación de las conferencias internacionales de Bruselas, de 1920, Génova, de 1922, y Lausana, de 1932, en 1938, en la Conferencia Panamericana de $\mathrm{Lima}^{16}$, se plantearon las propuestas para reemplazar las cuotas de importación por aranceles y el fomentar el principio de la igualdad de trato. Pero estas propuestas no tuvieron éxito, seguramente debido a la ausencia de un organismo que centralizara el interés común ${ }^{17}$.

Una vez ocurrida la Gran Depresión, el comercio internacional se centra fundamentalmente en una política aislacionista, de resguardo de intereses locales, sin intención alguna de promover la cooperación internacional. Prueba de ello fue el rotundo fracaso de la Conferencia de Londres de $1933^{18}$, que

15 Ibid., p. 462.

16 Estas Conferencias fueron promovidas en su época por la Sociedad de Naciones, y tenían como objetivo fundamental, a pesar de los objetivos individuales de cada una, promover acuerdos para la reconstrucción internacional, tanto comercial como financiera, fuertemente mermada tras la Primera Guerra Mundial.

17 GonZÁlez, S., Organización económica internacional. Relaciones y organismos fundamentales, Madrid, Pirámide, 2002, pp. 49-50.

18 A pesar de que la Conferencia Económica de Londres se llevó cabo, con la presencia de representantes de 66 naciones, se estima que ésta fue un fracaso, dada la negativa de Estados Unidos de participar en la misma. Dicho país mantenía una postura abiertamente aislacionista frente a una Conferencia que promovía la cooperación internacional. 
tenía como objetivo buscar una salida conjunta a la crisis generada por la depresión de 1929.

Posteriormente, y desde el fin de la Segunda Guerra Mundial, en particular con la creación de las Naciones Unidas, la comunidad internacional reconoció la urgente necesidad de crear y regular los canales que permitieran a los Estados una fluida relación económica internacional, y que tendiera a dinamizar de manera urgente la alicaída economía mundial de la post-guerra. Es así como surgen en los años venideros, una serie de instituciones internacionales encaminadas a facilitar, en su ámbito de aplicación y bajo las competencias concedidas en sus respectivos tratados constitutivos, la fluidez del comercio y la cooperación internacional. A modo de ejemplo, las propias Naciones Unidas, el Fondo Monetario Internacional (FMI), la Organización para la Cooperación y el Desarrollo Económico (OCDE), el Banco Mundial (BM) o el GATT, como tratado internacional, entre otros ${ }^{19}$.

A estos efectos, y de forma particular, resulta importante el carácter que asumen desde su creación, las Naciones Unidas. En el artículo 55, letras a) y b) de su Carta fundacional, se consagran expresamente la promoción de una serie de principios vinculados al mejoramiento, a través del desarrollo económico, de las condiciones de vida de las personas ${ }^{20}$ :

a. Niveles de vida más elevados, trabajo permanente para todos, y condiciones de progreso y desarrollo económico y social;

b. La solución de problemas internacionales de carácter económico, social y sanitario, y de otros problemas conexos; y la cooperación internacional en el orden cultural y educativo.

Sin perjuicio de lo anterior, esto no se logró ver materializado, dado el infructuoso intento de creación de un organismo internacional especializado

19 Schoenbaum, T.; Chow, D., International trade law. Problems, cases, and materials, New York, Wolter Kluwer, 2017, pp. 46-48.

20 El texto del artículo 55 de la Carta de las Naciones Unidas es más extenso, las letras expuestas se refieren de forma particular a asuntos vinculados a materias económicas y sociales. Al respecto, no sólo el artículo 55 de la Carta establece postulados en relación a la promoción y protección de asuntos económicos y sociales. Si bien, reconocemos que los objetivos centrales de Naciones Unidas son el mantenimiento de la paz y la seguridad internacionales, no es menos cierto que el objetivo económico y social por parte de la Organización está muy presente. Es así como, conjuntamente con el artículo 55, encontramos disposiciones vinculadas a la promoción de asuntos económicos y sociales, como lo son el artículo 1, apartado 3; artículo 13, apartado 1, letra b) y el artículo 62, apartados 1 y 2 . 
en el ámbito comercial, que hiciera frente a la promoción de los postulados del artículo 55 recién descritos. Es así, como la previsible ausencia de ratificación de la Carta Constitutiva de la Organización Internacional de Comercio (OIC), denominada comúnmente como la «Carta de la Habana» ${ }^{21}$, motivó que los países occidentales llevarán adelante paralelamente, negociaciones encaminadas a un similar fin, que concluyeron con la firma, el 30 de octubre de 1947, en la ciudad de Ginebra, Suiza, del llamado «Acuerdo General sobre Aranceles Aduaneros y Comercio», también conocido como GATT ${ }^{22}$. Este tratado internacional entró en vigor el 1 de enero de 1948, y fue suscrito por 23 países. Ya para 1988 eran 96 los Estados que formaban parte del Acuerdo. Este tratado tuvo como objetivo fomentar el incremento de las relaciones comerciales internacionales sobre una base igualitaria, eliminando progresivamente los aranceles y otras restricciones estatales ${ }^{23}$.

Heredero señala que en paralelo a la conformación de la OIC, se inició una negociación «más modesta» que buscaba como resultado un acuerdo provisional, que permitiera reducir la incidencia de barreras al comercio que se habían instalado en el comercio mundial en el periodo entre-guerras. Estas negociaciones dieron lugar a la conclusión del GATT en el que se codificaban los principales aspectos de las relaciones comerciales entre los Estados. Y tal como se señalaba, habiéndose iniciado como una negociación modesta y más bien provisional, se transformó en el único mecanismo multilateral para impulsar el comercio mundial de manera permanente ${ }^{24}$. La autora sostiene que, sin perjuicio del importante aporte que representó el GATT en el desarrollo del sistema de comercio internacional, la transitoriedad con la que se creó originó que durante su vigencia, «la regulación del comercio mundial haya estado marcada por la falta de consistencia y por el reconocimiento de numerosas excepciones respecto de los principios admitidos con carácter general» ${ }^{25}$.

$21 \mathrm{La}$ «Carta de la Habana» se firmó en la ciudad cubana del mismo nombre. La Conferencia se inició en noviembre de 1947 y finalizó en marzo de 1948. Al respecto, Vid. OIC. Conferencia de las Naciones Unidas sobre Comercio y Empleo. 1948. Disponible en https://www.wto.org/spanish/ docs_s/legal_s/havana_s.pdf

22 Esplugues, C., Derecho del comercio internacional, $3^{\text {a }}$ ed., Valencia, Tirant Lo Blanch, 2009, p. 28.

23 Casanovas, O.; Rodrigo, A., Compendio de Derecho internacional público, Madrid, Tecnos, 2012, p. 480.

24 Vid. Heredero, M.I., «La organización del comercio mundial y la división internacional del trabajo», en J.M. García y G. Durán (coords.), Sistema económico mundial, Madrid, Thomson Editores, 2008, p. 185.

25 Ibid., p. 186. 
Al mismo tiempo, y como ya señalábamos, se creaban dos importantes instituciones en la esfera de la cooperación para el desarrollo económico, el $\mathrm{BM}$ y el FMI ${ }^{26}$, que estaban vinculados a Naciones Unidas ${ }^{27}$, pero a diferencia de ellas, el GATT no era un organismo de las Naciones Unidas. Su elemento institucional básico era la Asamblea de las Partes Contratantes, que era su órgano decisorio máximo, y que actuaba y adoptaba acuerdos por mayoría de dos tercios de los países signatarios. Esta Asamblea se reunía dos veces al año. El GATT contaba además con una Secretaría y varios Comités en distintas áreas.

Brevemente descritas, las Conferencias celebradas bajo el GATT fueron ocho: La primera de ellas tuvo lugar en Ginebra, Suiza, en el año 1947, la que coincidió con la redacción del propio Acuerdo General; la Segunda Conferencia, también en la ciudad de Ginebra, en 1949; la Tercera Conferencia en Torquay, Inglaterra en 1951; la Cuarta en Ginebra en 1956 y la Quinta Conferencia también en Ginebra, en 1960, que recibiría el nombre «Ronda Dillon»-denominación que surge del apellido del Secretario del Tesoro de Estados Unidos de la época, Douglas Dillon-; la Sexta Conferencia denominada «Ronda Kennedy» de 1963 a 1967; la Séptima en Tokio, de 1973 a 1979 y la Octava Conferencia denominada la «Ronda Uruguay» de 1986 a $1994^{28}{ }_{2}^{29}$.

Desde 1995, con la creación de la OMC, se observa, desde el punto de vista institucional y de convergencia generalizada entre los Estados, una estructura comercial internacional consolidada, con objetivos y lineamientos claros en la materia, objetivos que procuran, por una parte, desde el punto de vista económico y de interés estatal, la facilitación y liberalización del comercio. Por otra parte, y en su condición de Organización internacional económica, procura la relación y el cumplimiento de sus objetivos en el vínculo comercial entre Estados, prescindiendo de la relación directa con las personas

26 Ambas instituciones creadas por los Acuerdos de Bretton Woods, de 1994. Al respecto, Vid.CopPELLI ORTIZ, G., «Influencia normativa de las Organizaciones Internacionales Económicas en los procesos de integración económica», Anuario Español de Derecho Internacional, n 30, 2014, p. 394.

27 En relación a la vinculación existente entre las instituciones señaladas con Naciones Unidas, Vid. http://www.bancomundial.org/es/about/partners

28 Tamames, R.; Huerta, B., Estructura económica internacional, $21^{\text {a }}$ ed., Madrid, Alianza Editorial, 2010, pp. 163-165.

29 El GATT en versión 1994, se complementa con una serie de acuerdos multilaterales, a saber: Acuerdo sobre Medidas Antidumping; Acuerdo sobre Subvenciones y Medidas Compensatorias; Acuerdo sobre la Aplicación de Medidas Sanitarias y Fitosanitarias; Acuerdo sobre Obstáculos Técnicos al Comercio. Estos últimos dos contienen normas específicas sobre barreras comerciales admisibles. Herdegen, M., Derecho internacional económico (traducción a cargo de Laura García y Katia Fach), Pamplona, Aranzadi, 2005, p. 168. 
y/o consumidores finales. Por tanto, cualquier objetivo que en esta materia se plantee esta Organización, como por ejemplo, mejorar el bienestar de las personas, reducir la pobreza y promover la paz y la estabilidad, son objetivos indirectos, que dependerán necesariamente del comportamiento de los Estados que componen la Organización, y no objetivos que la Organización pueda proponerse, ni menos cumplir de manera directa. Y ello, a pesar de que a través del Órgano de Solución de Diferencias (OSD) de la OMC, se convoquen a Estados, tanto en la instancia de consulta como de litigio propiamente tal, siendo normalmente intereses de particulares los motivos propios de consulta o litigio. Distinto resulta el cumplimiento de los objetivos planteados en las relaciones directas entre los Estados, como por ejemplo, los principios de Trato nacional y la Norma de la nación más favorecida (NMF), en donde la OMC tendrá injerencia directa en su cumplimiento ${ }^{30}$.

No obstante lo anterior, y aun sabiendo que la OMC establece reglas de acceso preferente a países menos adelantados ${ }^{31}$, respecto de los citados principios de Trato nacional y de la NMF, como principios generales, siempre resulta interesante cuestionarse si economías de distinto tamaño, y tan disímiles, como lo son aquellas que forman parte de la OMC, deben regirse por principios fundamentales que tienden a la igualdad, más que a la diferenciación o al reconocimiento de sus diferencias, y que ciertas distinciones sean más bien excepcionales y no generales ${ }^{32}$. Probablemente este ajuste mejoraría el acceso

30 Para los objetivos y visión general de la OMC, Vid. https://www.wto.org/spanish/thewto_s/ whatis_s/wto_dg_stat_s.htm. Respecto de la influencia normativa de la OMC, en su carácter de Organización económica internacional y la obligatoriedad de cumplimiento de sus resoluciones, Vid. COPPELli OrTiz, G., «Influencia normativa de las Organizaciones Internacionales Económicas en los procesos de integración económica», op. cit., pp. 393-429.

31 El Consejo Económico y Social de Naciones Unidas (ECOSOC) es el llamado a revisar, cada tres años, la lista de países menos adelantados (PMA). A marzo de 2018, 47 países son consignados en esta categoría. La condición de PMA le da derecho al país a acceso preferencial a los mercados internacionales y a asistencia técnica especial, entre otras concesiones. Sobre esta materia, vid. UNCTAD. Informe sobre los países menos adelantados 2017. Panorama General. Disponible en http://unctad.org/es/PublicationsLibrary/ldcr2017overview_es.pdf. Para conocer la lista de países menos adelantados Vid. ECOSOC. https://www.un.org/development/desa/dpad/ wp-content/ulloads/sites/45/ publication/ldc_list.pdf

32 Dentro del texto del Acuerdo General sobre Aranceles Aduaneros y Comercio (GATT) de 1947, el principio de la Nación más favorecida está contenido en su artículo primero, lo que da cuenta de la relevancia y trascendencia que éste tiene para el Acuerdo, al situarlo como el pilar de las reglas que regulan el comercio internacional. Lo mismo podría afirmarse respecto del principio de Trato nacional, que se encuentra contenido en el artículo III. Al respecto, Vid. OMC. https:// www.wto.org/spanish/docs_s/legal_s/gatt47_01_s.htm 
a mercados de productos y servicios de economías menos adelantadas, las cuales, hasta ahora, encuentran la «barrera» de Trato nacional en mercados más amplios y competitivos. Igual situación ocurre con el principio de la NMF, el cual hace extensiva las obligaciones suscritas con determinada economía al resto de los países que conforman el Acuerdo, con la consecuente y eventual desestabilización comercial de aquellos países que no puedan hacer frente a la aplicación de dicha medida, aun habiendo sido adoptada voluntariamente con particular Estado. Si de equidad en el comercio se trata, no parece ser una regla equitativa, sabido es que igualdad, no es lo mismo que equidad ${ }^{33}$.

Ya en 1964, y conjuntamente con la creación de la Conferencia de las $\mathrm{Na}-$ ciones Unidas para el Comercio y el Desarrollo (UNCTAD) ${ }^{34}$, se procuraba instaurar el principio de «desigualdad compensatoria», favorable a los países menos adelantados, buscando romper el esquema de reciprocidad imperante. Junto a ello, y en el mismo año, se modifica el GATT, incorporando una nueva parte IV denominada «Comercio y Desarrollo», que contenía una cláusula de no reciprocidad en las relaciones comerciales, entre países desarrollados y los que no lo sean, denominada «cláusula de habilitación» ${ }^{35}$, pero estructuralmente manteniéndose los principios centrales de NMF.

\section{EL PROTECCIONISMO FRENTE AL LIBRE COMERCIO: LA DEFENSA DE INTERESES INTERNOS}

Ya hemos reconocido, que la equidad en el comercio puede tener diversas manifestaciones, carencias o, en su caso, criterios de aplicación. Pero a la hora de su implementación, definir qué método resulta más eficiente

33 En relación a la necesaria distinción entre los Estados en materia económica, Casanovas y Rodrigo, señalan que «las relaciones económicas entre los Estados se encuentran sometidas a contradicciones muy marcadas, de muy difícil superación». Plantean que no obstante los Estados se consideran jurídicamente como iguales, en atención al principio de igualdad soberana de los Estados, por condición económica pueden ser muy distintos unos con otros. Este es el principal argumento que distingue entre países desarrollados y subdesarrollados. Las relaciones económicas entre los Estados procuran el beneficio propio, lo cual acentúa las desigualdades en favor de los países más ricos, mientras que el Derecho internacional procura la promoción de relaciones más equitativas. Vid. Casanovas, O.; Rodrigo, A., Compendio de Derecho internacional público, op. cit., p. 479.

34 UNCTAD son sus siglas en inglés y significa United Nations Conference on Trade and Develompent. Creada en 1964, con sede en Ginebra, es parte del sistema de Naciones Unidas, particularmente en materias de comercio y desarrollo. Para más, Vid. http://unctad.org/en/pages/ aboutus.aspx

35 Ibid. p. 481. 
parece ser la consigna a resolver. Por una parte, la implementación de una política económica proteccionista, que se traduce en el resguardo interno de los intereses del Estado, salvaguardando su industria nacional, su mano de obra e inversión, como clara muestra de equidad laboral para sus habitantes, obligatoriedad de inversión interna, además del fomento al desarrollo en innovación y emprendimiento interno, dada la escasa competencia internacional que se recibe. Y por otro lado, una política económica aperturista, viendo la equidad en el comercio, como el resultado del libre acceso a los bienes y servicios, en las mejores condiciones que pueda ofrecer el mercado, ya sea a través de productos nacionales o extranjeros, con un mínimo resguardo de la industria nacional, y potenciando aquellos emprendimientos dedicados a la importación y exportación de productos, que den movilidad y apertura a la economía local ${ }^{36}$.

En cualquier caso, bajo el actual modelo comercial internacional, podemos ver que las economías tienden a adoptar o una posición cerrada o una posición abierta, reconociendo que mayoritariamente los países se han inclinado por la segunda ${ }^{37}$. De todas maneras, es difícil imaginar una economía que se encuentre cerrada completamente, y al contrario, es imposible pensar que en una economía el librecambio sea completo. La regla general es que los países adopten posiciones más o menos abiertas y mantengan por tanto, en mayor o menor medida, relaciones comerciales con el resto de países. La teoría señala que la apertura de la economía al comercio internacional puede generar beneficios directos e indirectos en los intercambios, en la asignación de recursos, en la mejora de su competitividad internacional en relación a los productos que produce, entre muchos otros aspectos ${ }^{38}$.

Dicho lo anterior, y de lo analizado en contraposición al principio de equidad propiamente tal, surge el concepto de «proteccionismo» frente al libre comercio, entendiéndose como tal, una serie de conductas atentatorias o

36 Para analizar comentarios y críticas al modelo clásico de libre comercio, Vid. Peter GraY, H., A generalized theory of international trade, The MacMillan Press Ltd., London, 1976, pp. 12-14

$37 \mathrm{Al}$ respecto, Berumen plantea el «multilateralismo» como una tercera forma económica, o si se quiere, una tercera alternativa, basada en «una moneda patrón, con divisas nacionales convertibles y compensación de saldos periódicos entre los Estados involucrados, movimiento que se visualiza en los procesos integracionistas modernos», como por ejemplo, plantea, la realidad actual europea. Vid. Berumen, S., Economía internacional, México, Compañía Editorial Continental, 2002, p. 176.

38 MALFEITO, J., «El comercio internacional», en J. Malfeito (coord.), Introducción a la economía mundial, Madrid, Delta Publicaciones, 2012, p. 352. 
desleales, que afectan, de manera dolosa y arbitraria, los supuestos bajo los cuales se construye el libre comercio ${ }^{39}$.

No obstante lo anterior, como ya se señalaba someramente, existen distintos acuerdos internacionales, principalmente regulados por la $\mathrm{OMC}$, que confieren a los Estados la posibilidad de implementar las barreras, medidas u obstáculos que estimen convenientes para resguardar su industria y financiar en parte sus presupuestos, aunque no siempre estas medidas se aplican con la diligencia debida ${ }^{40}$. En algunas ocasiones se utilizan deslealmente, generando distorsiones y conflictos comerciales internacionales de diverso alcance.

El proteccionismo puede ser un caso concreto de aquello. Este consiste en el desarrollo de una política económica en la que, para proteger los productos del propio país, se imponen limitaciones a la entrada de productos extranjeros mediante la implementación de aranceles, o medidas no arancelarias (MNA) a la importación, que encarezcan el producto de tal manera que no sea rentable. En este sentido, Carrera, De Diego y Hernández sostienen que, «a pesar del rigor analítico y la elegancia formal de los modelos del comercio», en la práctica los países han seguido aplicando políticas proteccionistas con el fin de amparar sus industrias. Para ello recurren tanto a los aranceles como a barreras no arancelarias. Como principal efecto de la aplicación de estas medidas, se eleva el precio de los productos importados, permitiendo a la industria nacional menos eficiente, que pueda competir en mejores condiciones con las importaciones ${ }^{41}$.

39 A fines del siglo XVIII, se provocaba una particular dualidad de intereses entre el Nuevo Mundo, representado por los Estados Unidos y el viejo mundo representado por Europa y en particular Francia y Gran Bretaña. Europa, escasa en tierras, pero con importantes manufactureros, Estados Unidos por su parte, con abundante territorio, económico y fértil, muy a favor del libre comercio para la facilitación de la venta de productos agrícolas y materias primas a los mercados europeos. No obstante, iniciando el siglo XIX, en particular a través de la «Ley de Embargo» de 1807, Estados Unidos prohibió el comercio tanto con Francia como con Gran Bretaña, provocando una brutal caída en el comercio con ambos países, pero mejorando de forma importante la producción de manufactura local, que antes importaba desde Europa. En este sentido, vid. O’Rourke, K.; Williamson, J., Globalización e Historia, op. cit., pp. 155-156.

40 Es así, y tal como lo señala la OMC, «Los Acuerdos de la OMC obligan a los gobiernos a garantizar la transparencia de sus políticas comerciales notificando a la $\mathrm{OMC}$ las leyes en vigor y las medidas adoptadas. Diversos consejos y comités de la OMC tratan de asegurarse de que esas prescripciones se respeten y de que los Acuerdos de la OMC se apliquen debidamente. Todos los Miembros están sujetos a un examen periódico de sus políticas y prácticas comerciales, y cada uno de esos exámenes contienen informes del país interesado y de la Secretaría de la OMC». Disponible en https://www.wto.org/spanish/thewto_s/whatis_s/what_we_do_s.htm

41 Carrera, M.; De Diego, D.; Hernández, R., «Comercio internacional», en J.A. Alonso (dir.), Lecciones sobre economía mundial, $4^{\mathrm{a}}$ ed., Pamplona, Aranzadi, 2009, p. 209. 
La política proteccionista ha conocido distintos periodos de auge y decadencia. De forma general, en situaciones de economía de guerra o de autarquía, el proteccionismo se aplica de manera tajante. En situaciones de crisis económica, ciertos niveles de protección a los propios productos evitan, o tienden a evitar, bruscas caídas de precios y el consiguiente descalabro de algún sector de la economía nacional.

No obstante y a pesar de que conceptualmente entendemos el proteccionismo como una política atentatoria contra los flujos comerciales internacionales, hay quienes lo promueven. Es así como se plantea que el libre comercio está bien en la teoría, pero que no aplica en el mundo real. La teoría moderna del comercio asume mercados en competencia perfecta, cuyas características no reflejan las condiciones del mercado real. Los defensores del proteccionismo plantean, como bien jurídico protegido superior al flujo del comercio, entre otros, la protección del empleo interno; la protección contra el trabajo extranjero de bajo costo; la equidad en el comercio; mantener los estándares nacionales de vida y la seguridad nacional ${ }^{42}$.

En cualquier caso, y vinculado a lo anterior, diversas teorías asociadas al comercio internacional han planteado el debate acerca de las ventajas relativas al libre comercio y la protección. Al respecto Tugores señala que no se trata de elegir entre comercio o autarquía, sino de discutir en qué casos y que tipo concreto de limitaciones o restricciones pueden eventualmente mejorar los resultados del libre comercio. Plantea el autor que, al parecer, el mensaje más sensato es que «aunque conocemos las limitaciones teóricas del libre comercio, éste sigue siendo la referencia más válida de la que partir al discutir el sistema comercial más deseable» ${ }^{43}$.

A su vez, Calvo nos plantea el histórico enfrentamiento entre los partidarios del libre comercio y los que defienden la intervención del Estado en las relaciones internacionales. Frente al librecambio, y según las doctrinas proteccionistas, señala, el Estado debe asumir el papel de protector de la actividad económica, teniendo como justificación, para establecer impedimentos a la libre circulación de los bienes, argumentos de orden estrictamente económicos. En este sentido, la autora señala que los principales obstáculos al comercio

42 Vid. Carbaugh, R., Economía internacional, 12ª ed., México, Cengage Learning Editores, 2009, pp. 136-141.

43 Tugores, J., Economía internacional, globalización e integración regional, $5^{\text {a }}$ ed., Madrid, McGrawHill, 2002, p. 73. 
son, los arancelarios y los no arancelarios, sin perjuicio de otras medidas selectivas para proteger a la industria interna frente a las importaciones subvencionadas o con dumping ${ }^{44}$.

\section{DE LAS BARRERAS, OBSTÁCULOS Y RESTRICCIONES}

Antes de proceder al análisis de las distintas barreras y restricciones al comercio internacional, y su incidencia en la equidad del comercio, es importante contextualizar el tema realizando algunas definiciones generales de barreras, obstáculos, restricciones y otros conceptos que podrían entenderse como sinónimos pero que en la práctica presentan diferencias entre sí. Se entienden como sinónimos los conceptos de barrera y obstáculo, pero en una relación género-especie, siendo el género el obstáculo, la especie es la barrera.

Es en esta relación género-especie en la que podemos identificar separadamente, un alto número de barreras y obstáculos. Entre los obstáculos más relevantes encontramos la barrera propiamente tal, las prohibiciones, las cuotas, los contingentes, los cupos, los aranceles aduaneros, las licencias, los controles de tipo de cambio, las subvenciones, los depósitos previos, las reglas o procedimientos técnicos, las listas de mercancías de importación o exportación prohibidas, el proteccionismo, obstáculos técnicos al comercio, medidas sanitarias y fitosanitarias, entre otros. Todo, sin perjuicio de otros que podemos encontrar en relación a los servicios o en temas de propiedad intelectual ${ }^{45}$.

En este contexto, generalmente, sólo se consideran como barreras aquellas que dependen de la decisión de la autoridad gubernamental de un país. Sin embargo, es necesario reconocer otros factores que también pueden dificultar una operación en mercados extranjeros. Podemos señalar, por ejemplo, como

44 Calvo, A., Economía internacional y organismos económicos internacionales, Madrid, Centro de Estudios Ramón Areces, 2010, p. 189.

45 En particular, en lo que a comercio de servicios y propiedad intelectual se refiere, la OMC posee distintos Acuerdos, que de manera especial, regulan la aplicación de medidas que entorpezcan o limiten el libre comercio en estas materias. Es así como el Acuerdo General sobre el Comercio de Servicios, conocido por sus siglas GATS, o AGCS, también, al igual que el GATT, establece medidas sobre aplicación de la cláusula NMF, la obligación de favorecer el libre acceso a los mercados y normas de trato nacional, eso sí, limitadas según sea el sector comercial específico. En cuanto a la propiedad intelectual, a través del Acuerdo sobre los Aspectos de los Derechos de Propiedad Intelectual relacionados con el Comercio, conocido como TRIPS o ADPIC, procura el resguardo de patentes, marcas y derechos de autor entre otros. HerdegEn, M., Derecho internacional económico, op. cit., p. 169. 
adicionales a las barreras de orden político, las barreras físicas que dificultan al acceso a ciertos mercados, como accidentes geográficos o falta de infraestructura en comunicaciones, telecomunicaciones, vías de acceso, etc. ${ }^{46}$

Respecto de las restricciones, estas llevan implícita un obstáculo o una barrera como efecto o consecuencia de la imposición de la propia restricción. Es así como Fernández señala que como tipo de medida distinta de las barreras figuran, por ejemplo, las «restricciones cuantitativas», que las define como contingentes o topes máximos que un país autoriza a importar en un periodo determinado, ya sean generales o a un país en particular. «Restricciones de acceso al mercado» que tengan por objetivo dificultar gravemente o que directamente impidan el acceso a un mercado del producto de importación ${ }^{47}$.

En cuanto a su diferenciación, la primera y más clásica distinción que surge del concepto de barrera es el de barrera arancelaria y barrera no arancelaria, diferenciadas fundamentalmente por el pago, en el caso de las barreras arancelarias, de un impuesto por la importación de un producto. Si bien, esta clasificación será la que se aborda a continuación, reconocemos que existen otras ya señaladas con otros criterios de diferenciación, como por ejemplo barreras normativas o gubernamentales, barreras físicas, culturales y económicas.

Antiguamente, los aranceles constituían la forma clásica de reglamentación gubernamental del comercio, pero con el paso del tiempo esto ciertamente ha cambiado, no eliminando las barreras, sino más bien mutando su forma. Los niveles arancelarios se han reducido debido a la labor de liberalización realizada fundamentalmente por la OMC, pero sin perjuicio de ello, los gobiernos han buscado las formas de restringir el comercio sin violar los compromisos para reducir aranceles. Es así como han surgido y proliferado, las barreras no arancelarias, o como el Centro de Comercio Internacional (ITC) ${ }^{48}$ ha denominado genéricamente, MNA, convirtiéndose en el medio actual más activo de intervención en el comercio ${ }^{49}$.

46 Berumen, S., Economía internacional, op. cit., 171.

47 FERnándeZ, JC., Sistema de derecho económico internacional, op. cit., p. 160.

$48 \mathrm{El}$ Centro de Comercio Internacional, conocido por sus siglas en inglés ITC (International Trade Centre), es la agencia conjunta de la OMC y las Naciones Unidas, representada a través de UNCTAD. Con sede en Ginebra, Suiza, fue creada en el año 1964, y tiene como finalidad, entre otras, fomentar el crecimiento y desarrollo inclusivos y sostenibles a través del comercio y desarrollo empresarial internacional.

49 Ingram, J.; Dunn, R., Economía internacional (traducción a cargo de Alfredo Díaz), Ciudad de México, Limusa, 2001, p. 146. 


\section{El arancel, concepto y efectos ${ }^{50}$}

Para la OMC, los aranceles son derechos de aduana aplicados a las importaciones de mercancías. Es un tipo de impuesto que grava la entrada de productos extranjeros al mercado local. Estos aranceles, junto con proporcionar a las mercancías producidas en un país una ventaja en materia de precios con respecto a las mercancías similares importadas, representan una fuente de ingresos para los gobiernos dado su carácter impositivo. Como resultado de la Ronda Uruguay, que como ya señalábamos se realizó entre los años 1986 y 1994, que representa el nacimiento de la OMC a través de la Conferencia de Marrakech, se tuvo el compromiso de los países miembros, de reducir los aranceles, de manera permanente y consistente, y consolidar los tipos de derechos de aduanas en cada uno de ellos. Cada país, a través de las listas anexas al Convenio, informa de sus aranceles base, los cuales, una vez notificados a la Organización, no podrán ser modificados unilateralmente.

Los aranceles, siendo cobros aduaneros que se establecen sobre las importaciones de las mercancías en la frontera de cada país, encarecen esos bienes en el mercado interno. Estos aranceles, según señala $\mathrm{Calvo}^{51}$, «penalizan» tanto a los productores extranjeros, como a los consumidores nacionales, actuando en favor de los productores nacionales y del gobierno, ya que estos son ingresos fiscales, protegiendo o «blindando» por tanto, al productor nacional de la competencia extranjera, e incrementando directamente las arcas fiscales por la vía de la recaudación impositiva. De la definición de arancel, surge una clasificación más bien genérica, agrupándolos en: específicos, ad valorem o mixtos. Los específicos son aquellos que se calculan en función de la cantidad física del producto o según la unidad del producto. Los ad valorem se calculan según un porcentaje del valor del producto y los aranceles mixtos son una combinación de los dos anteriores. Otra clasificación que podemos encontrar de arancel es la de, arancel compensatorio o antidumping y arancel de tránsito, entre otros ${ }^{52}$.

Según plantea Fernández, el arancel representa el instrumento base del intervencionismo del poder público, y lo define como «aquella carga econó-

50 Diversos ejemplos y ejercicios sobre la conveniencia y efectividad en la imposición de estructuras arancelarias encontramos en nutrida bibliografía científica. Vid. entre otros, BERUMEN, S., Economía internacional, Ciudad de México, Continental, 2002, pp. 152-154; ReQueIJo, J., Economía mundial, op. cit., pp. 32-34.

51 Calvo, A., Economía internacional y organismos económicos internacionales, op. cit., p. 190.

52 Para el detalle y definiciones de cada tipo de arancel, Vid. FERnÁnDEZ, J.C., Sistema de derecho económico internacional, op. cit., p. 162; BERUMEN, S., Economía internacional, op. cit., p. 145. 
mica que se aplica a las mercancías cuando son importadas de otro país». Detalla el autor, que en términos más concretos, el arancel es una tarifa oficial prevista en una norma jurídica, que determina los derechos que han de pagarse sobre la importación de mercancías y que se establece de conformidad a las necesidades de la economía de un Estado. Su implementación, plantea, genera diversos efectos generales, entre los cuales cabe destacar, el incremento de la recaudación de un Estado; la disminución de las importaciones; aumento de la producción nacional, entre otros ${ }^{53}$.

En este sentido Feenstra y Taylor señalan diversos efectos del arancel, pero estableciendo la distinción entre efectos ocasionados en países pequeños y efectos en países grandes ${ }^{54}$. La división entre país pequeño y país grande la plantean considerando que un país es pequeño, para estos efectos, cuando su arancel no provoca efecto alguno sobre el precio mundial del bien sobre el que se aplica el arancel. Al contrario, el arancel aplicado por un país grande implicaría la modificación o alteración del precio mundial. Los autores plantean que para un país pequeño, un arancel siempre provocaría una pérdida de eficiencia. No obstante, siendo una rápida y sencilla vía de financiamiento, el arancel se sigue utilizando. Para un país grande, en cambio, su bienestar puede mejorar gracias al arancel ${ }^{55}$.

Una apreciación también interesante, es la que hace la ITC, señalando que los niveles arancelarios siguen siendo altos e imponen fuertes restricciones al comercio de países en desarrollo. Estos niveles, señala, «no sólo afectan al comercio entre países en desarrollo y países desarrollados, sino también al comercio entre los propios países en desarrollo. Las «crestas arancelarias» ${ }^{56}$ en productos básicos fundamentales, en particular agrícolas, y la progresión arancelaria han tenido para los países en desarrollo una serie de consecuencias, como por ejemplo, reducir el comercio de estos productos básicos fundamen-

53 Vid. FernánDEZ, J.C., Sistema de derecho económico internacional, op. cit., p. 161.

54 Para ejemplos que ayuden a distinguir económicamente un país grande de un país pequeño, vid. Tugores, J., Economía internacional e integración económica, Madrid, McGraw-Hill, 1994, p. 48.

55 Feenstra, R.; TAYlor, A., Comercio internacional, Barcelona, Reverte, 2011, pp. 281-291.

56 Las «crestas arancelarias» son derechos de aduana relativamente altos, que se destacan por encima del nivel medio del arancel y suelen aplicarse a productos «sensibles». En el caso de los países industrializados, se considera por regla general que los derechos del $15 \%$ o más constituyen «crestas arancelarias». Suelen ser utilizadas, en mayor medida por países desarrollados, más que para la protección de la industria nacional, para obtener un incremento de la recaudación fiscal. Al respecto cfr. OMC. Disponible en http://www.wto.org/spanish/thewto_s/glossary_s/ tariff_peaks_s.htm 
tales; la progresión arancelaria desvía las exportaciones de países en desarrollo hacia productos o mercados con aranceles más bajos, lo cual limita sus oportunidades de diversificación», entre otras consecuencias ${ }^{57}$.

\section{Las barreras no arancelarias}

Como se señalaba anteriormente, establecer una clasificación de restricciones al comercio resulta casi imposible, más aún en lo que a barreras no arancelarias (BNA) se refiere. No obstante lo anterior, y con la finalidad de adoptar al menos una línea de sistematización, revisaremos la clasificación que para estos efectos realiza la ITC, denominadas MNA.

En todo caso, y según lo distingue la propia ITC, las MNA y BNA no debieran considerarse sinónimos, ya que en el contexto del comercio internacional es muy importante hacer una distinción entre ambas. Plantean que una MNA es un «concepto neutral», es decir, son medidas que pueden tener un impacto positivo o negativo sobre el comercio o incluso no tener ninguno. Muchas de las MNA, señala la ITC, introducidas recientemente, reflejan la creciente sofisticación de la demanda de los mercados y consumidores, apuntando, por ejemplo, al cuidado de la salud de las personas o animales, y por tanto, no se ve necesario suprimirlas. Las BNA en cambio, conllevan siempre un impacto negativo en su correspondiente aplicación. Algunas BNA provienen de las MNA, pero otras, como la distancia, no guardan ninguna relación ${ }^{58}$.

Esta dualidad resulta clave, por cuanto nos acerca a la distinción técnica fundamental, que se hace de aquellas barreras encaminadas a poner a la persona como el fin último y por ende, como el bien jurídico protegido, versus aquellas barreras de negativo impacto en sus objetivos, sea comercial o en atención a la persona. Dicha distinción es necesaria para identificar un comercio equitativo, sea éste primeramente en función de las personas, o bien, en segundo término, en función del comercio y la recaudación del Estado como una sola vía de financiación.

Carbaugh plantea el aumento de este tipo de medidas, fundamentalmente a partir de los años sesenta, siendo uno de los temas de mayor discusión en

57 Vid. ITC. Acceso almercado, transparencia y equidad en el comercio mundial, Ginebra, 2010. p. 26. Disponible en http://www.intracen.org/acceso-al-mercado-transparencia-y-equidad-en-el-comercio-mundial/

58 ITC. Acceso al mercado, transparencia y equidad en el comercio mundial, op. cit., p. 41. 
las rondas actuales de negociaciones internacionales. Señala el autor, que aunque los aranceles han disminuido, las BNA al comercio se han multiplicado. Esto como resultado de la búsqueda de otros canales distintos de los aranceles para la protección de la producción interna. De todas maneras, el autor reconoce que no todas las BNA tienen consecuencias comerciales de importancia. Por ejemplo, plantea, los empaques y etiquetado pueden llegar a restringir el comercio pero de manera marginal. No así el caso del establecimiento de cuotas de importación, restricciones voluntarias a la exportación, subvenciones y requerimientos de contenido nacional, todas las cuales pueden llegar a afectar de forma significativa los patrones comerciales ${ }^{59}$.

Para Fernández, son barreras comerciales menos evidentes que los aranceles pero en ocasiones mucho más efectivas, al constituir importantes obstáculos al comercio internacional. Señala que estas BNA pueden estar constituidas tanto por normas legales, así como por procedimientos administrativos basados en directivas más bien informales. De ahí que su determinación, plantea el autor, no sea una operación fácil. Sin perjuicio de lo anterior, señala que pueden llegar a tener objetivos legítimos, es por ello que pueden introducirse de forma compatible con el régimen de la $\mathrm{OMC}^{60}{ }^{61}$.

En otro sentido, Tugores señala que la imposición de requisitos técnicos o sanitarios son buenos ejemplos de este tipo de $\mathrm{BNA}$. $\mathrm{Al}$ respecto el autor plantea que estas «son disposiciones cuya finalidad declarada es la «garantía de calidad» de los productos alegando preocupaciones bien vistas en la opinión pública, como la defensa de los consumidores, la salud pública o el medio ambiente. Pero eligiendo «astutamente» los detalles de las especificaciones técnicas se produce el efecto de dejar fuera del mercado, o imponer costes adicionales, a productos extranjeros ${ }^{62}$.

Regularmente, y de forma lícita, la implementación de BNA son decididamente intencionales, pero en algunas ocasiones, con un disfraz o apariencia de perseguir un objetivo económico, lo que dado su carácter, resultan una

59 Carbaugh, R., Economía internacional, op. cit., p. 150.

60 Cuando se habla de un objetivo legítimo, los artículos XX y XXI del GATT, permiten la adopción de estas medidas siempre que no se utilicen como una restricción encubierta al comercio internacional, cuando las mismas estén destinadas a:

a) Proteger la moral pública; b) Proteger la vida y salud de las personas, los animales y a los vegetales; c) Comercio de materiales nucleares; d) Comercio de armas y municiones; e) Recursos naturales agotables; f) Protección del medio ambiente.

61 FERnÁndeZ, JC., Sistema de derecho económico internacional, op. cit., p. 166.

62 Tugores, J., Economía internacional, globalización e integración regional, op. cit., p. 71. 
forma posible de mantener fuera del mercado local la importación de determinados productos extranjeros ${ }^{63}$.

\section{A. Clasificación de BNA}

De los argumentos expuestos, podemos señalar que las BNA son disposiciones gubernamentales que obstruyen el ingreso de mercancías a un país determinado poniendo como requisito para admitir su ingreso que los productos y servicios cumplan con determinadas reglas o que reúnan ciertos requisitos de distinto orden. O bien, como las define la ITC, «disposiciones políticas (salvo los derechos de aduana ordinarios) por las que se rigen la exportación y la importación, y pueden tener un efecto económico sobre el comercio internacional $\gg^{64}$.

Tal como apuntamos anteriormente una primera distinción de BNA es la propia distinción que hace la ITC al respecto, agrupando según efectos, «neutral» o no, las barreras o medidas, indicando que serán MNA las que tengan un efecto sea positivo, negativo o ningún efecto, y las BNA las que persiguen un efecto sólo negativo, nocivo y atentatorio contra el libre comercio internacional, protegiendo ilegítimamente los intereses del Estado o productores internos. Si bien la doctrina imperante no tiene del todo asimilada dicha distinción conceptual que intenta imponer la ITC, si podemos constatar que los autores reconocen diferencias nocivas, perjudiciales, o bien favorables según las distintas barreras -o medidas- que hagamos referencia, reconociendo, en cualquier término las diferencias existentes en sus resultados económicos y extra económicos.

Otra modalidad de obstáculos no arancelarios son los que Calvo señala como «restricciones voluntarias a la exportación», como medidas que evitan la normativa multilateral. Al respecto, señala la autora, en la Ronda Uruguay se decidió eliminar las limitaciones voluntarias a las exportaciones y la supresión progresiva del sistema de contingentes en algunos sectores como por ejemplo textil y agricultura por los países desarrollados, así como la exigencia de mayor transparencia en la notificación de las normas y reglamentos técnicos ${ }^{65}$.

63 IngRam, J.; DunN, R., Economía internacional, op. cit., p. 151.

64 ITC. Acceso al mercado, transparencia y equidad en el comercio mundial, op. cit., p. 40.

65 Calvo, A., Economía internacional y organismos económicos internacionales, op. cit., p. 193. 
Figura Explicativa

Resumen de medidas no arancelarias (MNA) para la importación

Capítulos

\begin{tabular}{cll}
\hline Medidas & A & Medidas sanitarias y fitosanitarias (MSF) \\
\cline { 2 - 3 } técnicas & B & Obstáculos técnicos al comercio (OTC) \\
\hline $\begin{array}{c}\text { Medidas } \\
\text { no } \\
\text { técnicas }\end{array}$ & $\mathrm{C}$ & Inspección previa a la expedición y otras fórmulas \\
\cline { 2 - 3 } & $\mathrm{D}$ & Medidas de control de precios \\
\cline { 2 - 3 } & $\mathrm{E}$ & Licencias, contingentes, prohibición y otras medidas de control \\
\hline & $\mathrm{F}$ & Gravámenes, impuestos y otras medidas paraancelarias \\
\hline $\mathrm{H}$ & Medidas financieras \\
\hline $\mathrm{I}$ & Medidas anticompetitivas \\
\hline & $\mathrm{J}$ & Restricciones distributivas en materia de inversiones relacionados al comercio \\
\hline $\mathrm{K}$ & Restricciones sobre los servicios postventas \\
\hline $\mathrm{L}$ & Subvenciones (excluidas las subvenciones a la exportación) \\
\hline $\mathrm{M}$ & Restricciones en la contratación pública \\
\hline $\mathrm{N}$ & Propiedad intelectual \\
\hline $\mathrm{O}$ & Normas de origen \\
\hline
\end{tabular}

Fuente: ITC

* Este resumen de MNA, que incorpora una taxonomía internacional, ha sido elaborado por un grupo de expertos técnicos pertenecientes a ocho organizaciones internacionales, la FAO, FMI, ITC, OCDE, UNCTAD, ONUDI, BM y OMC. Este resumen se utiliza para recoger, clasificar, analizar y difundir la información de fuentes oficiales sobre las MNA. Cfr. ITC. Acceso al mercado, transparencia y equidad..., op. cit., p. 50. Adicionalmente, la presente clasificación de MNA distingue entre las diferentes medidas, con arreglo a 16 capítulos (identificados cada uno con letras alfabéticas).

Según plantea la propia ITC, las MNA incluyen una gran variedad de instrumentos, como son, las medidas sanitarias y fitosanitarias (MSF), los obstáculos técnicos al comercio (OTC), medidas anticompetitivas, licencias de importación, restricciones a la exportación, recargos aduaneros, medidas financieras y medidas antidumping. Estas MNA suelen ser menos transparentes y de más difícil implementación que los aranceles, y por tanto, desde el punto de vista de la determinación y cuantificación de las inversiones resultan mucho más complejas de determinar ${ }^{66}$.

66 Complementando lo anterior, según encuesta realizada por la propia ITC, las MNA constituyen uno de los tres principales factores de preocupación en la esfera del comercio. Las encuestas de la ITC indagan sobre las MNA, en particular, en el comercio de mercancías. En estas entrevis- 
$\mathrm{Al}$ respecto, y considerando en parte los ejemplos citados, existen diversas clasificaciones de barreras no arancelarias, de las cuales podemos principalmente señalar dos grupos: las barreras o medidas técnicas, y las no técnicas ${ }^{67}$.

\section{B. Otras BNA}

Para Ossa, la literatura económica ha usado distintos casos en que se presentan distorsiones domésticas al comercio, inflexibilidades de precios e inmovilidad de factores para justificar, según señala, el uso de políticas proteccionistas. En algunos de estos casos, se puede demostrar la posibilidad - no así la necesidad, sostiene - de que el libre comercio traiga por resultado que la comunidad alcance un nivel de bienestar más bajo que el que existiría con restricciones al intercambio. No obstante aquello, el autor señala que de esta posibilidad no se pueden deducir argumentos en favor del uso de controles al comercio internacional, debiéndose aplicar en cambio subvenciones, gravámenes e impuestos para eliminar o disminuir la distorsión en donde esta se produzca $^{68}$.

Es en base a este criterio de los mercados y del comercio, que podemos identificar otro tipo de BNA. Ello, sin perjuicio del análisis realizado precedentemente de las BNA, con su efecto propio negativo en su aplicación, reconocidas así en el comercio internacional y fundamentalmente en los distintos Acuerdos vinculados a la materia, emanados de la $\mathrm{OMC}$. $\mathrm{Y}$ es que dado este carácter, existen algunas BNA que vale la pena analizar de manera separada. Son aquellas que tienen más bien una mirada «proteccionista» y que son obstáculos al comercio internacional que imponen los gobiernos, pero no como una barrera en sí misma, sino como una respuesta al comercio desleal que surge por ejemplo, de actuaciones de terceros Estados, como las subvenciones o el dumping. Así encontramos las denominadas cuotas de importación, derechos compensatorios, medidas antidumping y salvaguardias, entre otras barreras, que vienen a ser

tas, a través de cuestionarios, se determina que MNA y obstáculos al comercio son excesivamente onerosos y frecuentes, a través del método de muestreo al azar, a un determinado número de empresas, que regularmente fluctúan entre las 300 y las 1500 empresas por país. Cfr. ITC. Acceso al mercado, transparencia y equidad..., op. cit., pp. 40-41.

67 Ibid., p. 40.

68 Ossa, F., Economía internacional, aspectos reales, $3^{\mathrm{a}}$ ed. ampliada, Santiago de Chile, Universidad Católica de Chile, 2006, p. 238. 
una respuesta a la cuestión planteada. Pero no se puede analizar la medida que adopta el Estado si no se analiza la conducta que lo genera.

a) Los contingentes o cuotas de importación

Los contingentes o cuotas de importación son aquellos caracterizados por limitar la cantidad física del bien o servicio que puede importarse. Estos adquieren la calidad de BNA cuando no forman parte de un compromiso específico de acceso al mercado en el marco de un acuerdo comercial. Se plantean como un tipo de «proteccionismo» en el que se limita la cantidad total de importaciones de una determinada mercancía durante un periodo de tiempo ${ }^{69}{ }_{-}{ }^{70}$.

Fueron los obstáculos más utilizados antes de la Segunda Guerra Mundial, y por regla general, o eran impuestos de forma unilateral y administrados por los gobiernos de los países importadores o eran el resultado de la división de los mercados internacionales por los recursos naturales o las empresas que dominaban el comercio ${ }^{71}$.

Una práctica común para administrar una cuota de importación, son las llamadas «licencias de importación». En cada licencia se especifica el volumen de importaciones permitido y el volumen total no debe exceder dicha cuota. Estas licencias pueden venderse a empresas importadoras a un precio competitivo o simplemente a una tarifa, o en lugar de venderlas, el gobierno puede otorgarlas a sus importadores cercanos. Según Carbaugh, este método se muestra abiertamente como un sistema que se presta para prácticas de soborno o arreglo político ${ }^{72}$.

Conocido el objetivo que cumplen las cuotas de importación, resulta necesario hacer una distinción o relación, con lo que representaría directamente la imposición de un arancel. Si lo ponemos en contraposición, podríamos escoger la opción de gravar el precio de un producto, a través del sobreprecio que representa el arancel, o bien, limitar su ingreso al mercado a través de la imposición de una cuota. La relación la podemos hacer a la luz del consumidor

69 A pesar de que el GATT eliminó las cuotas para los bienes manufacturados, éstas son cada vez más comunes, pero a través de las modernamente denominadas «restricciones voluntarias a la exportación». Con este tipo de restricciones voluntarias, el país importador no mantiene un límite sobre la cantidad importada, y por tanto son los países exportadores quienes voluntariamente limitan el volumen de envíos hasta lo previamente acordado. En este sentido, vid. INGRAM, J.; DUNN, R., Economía internacional, op. cit., p. 152.

70 FERnÁNDEZ, J.C., Sistema de derecho económico internacional, op. cit., p. 167.

71 Calvo, A., Economía internacional y organismos económicos internacionales, op. cit., p. 193.

72 Carbaugh, R., Economía internacional, op. cit., p. 150. 
final, quien se vería enfrentado a disponer de un número ilimitado de productos, pero más caros, por el incremento del precio que representa el arancel versus producto más barato en su precio inicial, pero quizás por ser una oferta más escasa, y existir un límite en su ingreso derivado de la cuota, se traduzca en un precio más caro todavía. En concreto podemos señalar por tanto, que si bien una cuota tendría un efecto restrictivo a la importación frente al arancel, el arancel como efecto inmediato encarece el precio del producto vendido en el país receptor.

De esta distinción existente entre las cuotas y el arancel, ha surgido el concepto de «tarificación», que es el resultado de la decisión de los países miembros de la $\mathrm{OMC}$, en el sentido de eliminar progresivamente las cuotas de importación, privilegiando en su reemplazo la aplicación de aranceles. Entendemos que esta solución no resulta del todo positiva, pero al menos liberaliza la posibilidad de tráfico de mercancías, que si bien, previamente, podían estar limitadas por la aplicación de una cuota, hoy podrán ser comercializadas con la sola limitación del pago del derecho de importación, ciertamente en el entendido que junto a lo anterior, no apliquen selectivamente ciertas MNA para el tratamiento de las mismas mercancías.

\section{b) Las subvenciones ${ }^{73}$}

Las subvenciones son otro tipo de BNA, que consisten en acciones de gobiernos tendentes a favorecer a una determinada actividad, por la vía de ayudas económicas otorgadas de forma directa. El efecto inmediato que la subvención tiene para quien la recibe, es que hace sus productos más competitivos en los mercados internacionales, contando con la posibilidad de mejorar su producción, bajar sus precios o ambas. Es decir, la subvención es ayuda interna, para competir en mejores condiciones -no siempre lícitas- en los mercados internacionales. La diferencia de la subvención con el dumping, es que la primera nace de la mano del Estado que es el directo colaborador en el subsidio a la industria privada en particular.

73 No obstante a que tienden a usarse como sinónimos, «subvenciones» y «subsidios» pueden no ser lo mismo. Si bien ambas son ayuda financiera o económica de un Estado o de un organismo público, una subvención contribuye a mejorar los costos en la fabricación o producción de algún producto, haciéndolo más competitivo en los mercados internacionales. El subsidio en cambio, es una ayuda directa que satisface una necesidad puntual y acotada. Dada esta distinción, ciertamente entendemos que las disposiciones referidas al libre comercio y las normas que regulan la materia por parte de la OMC se refieren a subvenciones. 
Ya en el Acuerdo GATT de 1947 se incluía en el artículo XVI una obligación de notificación de las partes contratantes respecto de cualquier subvención que tuviera como efecto, directa o indirectamente, aumentar las exportaciones de un producto cualquiera, o reducir las importaciones de este producto en su territorio ${ }^{74}$.

Si bien el arancel y los contingentes tienen en principio el mismo impacto en el mercado, no ocurre así con las subvenciones. Tanto el arancel como la cuota están destinados a incentivar el aumento de la producción nacional, el subsidio en cambio, está orientado a lograr un efecto equivalente en dicha producción. Por tanto, a través de un subsidio equivalente, la industria nacional tendría un beneficio similar al del arancel. Sin perjuicio de que para la OMC el subsidio no se encuentra prohibido, existe un acuerdo denominado «Acuerdo sobre Subvenciones y Medidas Compensatorias», cuyo objetivo central es eliminar cualquier intervención del Estado que se produzca a través de la concesión de subvenciones en materia de exportaciones, buscando de esa manera eliminar distorsiones en el comercio internacional ${ }^{75}$.

Este Acuerdo señala que existe subvención, cuando un gobierno, o un organismo público ${ }^{76}$, realicen una contribución financiera o lleve a cabo cualquier otra forma de sostenimiento de los ingresos o los precios ${ }^{77}$.

Resulta importante señalar que, una «medida compensatoria» no obedece al concepto de BNA, y se refiere principalmente a aquella medida que puede aplicar un Estado con el fin de contrarrestar una subvención otorgada a un producto por parte del Estado productor del bien, a condición de que esa subvención cause daño a un sector de la producción nacional que produzca bienes similares. La medida compensatoria es a la subvención como las medidas antidumping lo son al dumping.

Dicho Acuerdo establece fundamentalmente dos categorías de subvenciones: las llamadas «subvenciones prohibidas»y las «subvenciones recurribles» ${ }^{78}$.

74 LóPeZ-JuRado, C.; MarTíN, P., «La regulación material del comercio internacional», en L. Hinojosa y J. Roldán (coords.), Derecho internacional económico, Madrid, Marcial Pons, 2010, pp. 112.

75 FERnándeZ, JC., Sistema de derecho económico internacional, op. cit., p. 187.

76 Estamos en presencia de un «organismo público», cuando se produce el control del Estado en la participación de una empresa a través de: el capital de la empresa; el nombramiento de sus órganos directivos por parte del Gobierno y a la aprobación de los programas de gestión anual. LóPEzJURADO, C.; MARTÍN, P., «La regulación material del comercio internacional», op. cit., p. 114.

77 Cfr. OMC. https://www.wto.org/spanish/tratop_s/scm_s/scm_s.htm

78 Inicialmente, este Acuerdo sobre Subvenciones y Medidas Compensatorias, contenía una tercera categoría, las denominadas «subvenciones no recurribles». Esta categoría existió durante cinco años, eliminándose con posterioridad, concretamente el 31 de diciembre de 1999. 
El Acuerdo señala que son subvenciones prohibidas, «aquellas cuya concesión está supeditada al logro de determinados objetivos de exportación o a la utilización de productos nacionales en vez de productos importados». Estas subvenciones están prohibidas ya que están destinadas específicamente a distorsionar el comercio internacional y, por consiguiente, es probable que perjudiquen al comercio de los demás países. Pueden impugnarse mediante el procedimiento de solución de diferencias de la OMC, que prevé para ellas un calendario acelerado. Si en el procedimiento de solución de diferencias se confirma que la subvención figura entre las prohibidas, esta deberá suprimirse inmediatamente. De lo contrario, la parte reclamante puede adoptar contramedidas. Si las importaciones de productos subvencionados perjudican a los productores nacionales, podrá imponerse por parte del Estado afectado un derecho compensatorio.

En las subvenciones recurribles, en cambio, el país reclamante tiene que demostrar que la subvención tiene efectos desfavorables para sus intereses. De no ser así, se permite la subvención. En el Acuerdo se señalan tres tipos de perjuicios que las subvenciones podrían ocasionar: en primer término, pueden ocasionar un daño a una rama de producción de un país importador; en segundo lugar pueden perjudicar a los exportadores rivales de otro país cuando unos y otros compitan en terceros mercados; y en tercer término, las subvenciones internas de un país pueden perjudicar a los exportadores que traten de competir en el mercado interno de dicho país. Si el Órgano de Solución de Diferencias (OSD) dictamina que la subvención tiene efectos desfavorables para la actividad comercial del Estado reclamante, se deberá suprimir la subvención o eliminar sus efectos desfavorables. También en este caso puede imponerse un derecho compensatorio si las importaciones de productos subvencionados perjudican a los productores nacionales ${ }^{79}$.

En otros términos, las subvenciones se pueden clasificar en los llamados «subsidio a la producción nacional» y el «subsidio a la exportación». En el caso del primero se refiere a aquel subsidio concedido a los fabricantes locales de los productos que compiten en las importaciones, y en el segundo caso, se refiere al subsidio aplicado a quienes venden sus productos en el extranjero. En este tipo de subvenciones, el Estado agrega una cantidad sea de manera directa o indirecta, al precio que el comprador deba pagar por un determinado producto. Así por ejemplo, se puede decir que, el valor neto recibido por el productor, será el mismo que el valor pagado por el comprador, más el

79 OMC. Disponible en http://www.wto.org/spanish/thewto_s/whatis_s/tif_s/agrm8_s.htm 
subsidio $^{80}$. Por tanto, el productor subsidiado estará en condiciones de ofrecer una mayor cantidad de productos, o bien a menor precio final, o bien a mayor precio pero con mayor utilidad.

\section{c) El dumping}

A las barreras ya señaladas, las cuales tienen directa o indirectamente una fuerte influencia estatal en su creación o aplicación, se suman otras que nacen más bien de la propia actividad privada, que además de plantearse como un obstáculo, las distinguimos como una competencia desleal. En este concepto encontramos «el dumping».

Para Canabellas y Saravia ${ }^{81}$, la definición de dumping presenta aspectos sustancialmente distintos según se refieran a él por parte de una legislación determinada o no. Señalan los autores que dado que el concepto de dumping varía radicalmente en función de la posición económica que se elija para definirlo, sólo la existencia de una definición legal permite llegar a un grado aproximado de certeza respecto de un concepto que contenga todas sus características, o al menos contenga los fines del sistema jurídico en el cual tal definición ha sido impuesta. Según señala la OMC, en el denominado «acuerdo antidumping», si una empresa exporta un producto a un precio inferior al que aplica normalmente en el mercado de su propio país, se dice que hace dumping. Si bien el respectivo Acuerdo de la OMC no regula las acciones de las empresas que incurren en dumping, sí plantea la forma en que los Estados pueden o no reaccionar ante el dumping, estableciendo disciplinas para las medidas antidumping ${ }^{82}$.

El dumping no es condenado de forma absoluta por la OMC, sino sólo cuando tiene por efecto causar o amenazar con causar un daño importante a un sector de la producción nacional del país importador. Existen en el Acuerdo de la OMC reglas para la determinación del daño, como por ejemplo, la posibilidad de analizar globalmente el impacto en el mercado importador de las exportaciones objeto de dumping procedentes de diversos países, facilitando de esta manera la determinación del dumping condenable ${ }^{83}$.

80 CARbaUgh, R., Economía internacional, op. cit., p. 162.

81 Canabellas, G.; Saravia, B., Dumping, subsidios y salvaguardias, Buenos Aires, Heliasta, 2006, p. 83

82 OMC. Disponible en http://www.wto.org/spanish/tratop_s/adp_s/adp_s.htm

83 LÓPEZ-JURADO, C.; MARTíN, P., «La regulación material del comercio internacional», op. cit., pp. 109-110. 
Existen diversas formas de calcular si un determinado producto es objeto de dumping en un grado significativo o no. El Acuerdo expone tres métodos para calcular lo que él llama «valor normal» del producto. El principal de ellos se basa en el precio del producto en el mercado del país exportador. Cuando no puede utilizarse ese método, existen dos alternativas: el precio aplicado por el exportador en otro país o bien un cálculo basado en la combinación de los costos de producción del exportador, otros gastos y márgenes de beneficio normales. El Acuerdo determina asimismo cómo realizar una comparación equitativa entre el precio de exportación y lo que sería un precio normal ${ }^{84}$.

Si bien no se contempla en el presente trabajo desarrollar las formas de defensa de los agentes afectados por la aplicación injusta de alguna barrera, es importante al menos señalar que, de todas las barreras analizadas, la OMC considera una serie de medidas que puede utilizar el comerciante para la debida protección de sus intereses, conocidas como «mecanismos de defensa comercial ${ }^{85}$, los cuales para ser invocados deberán hacerse a través del Estado del comerciante o agrupación de comerciantes afectados. Entre estos mecanismos caben destacar las medidas antidumping, los derechos compensatorios y salvaguardias.

El dumping, en atención a diversos factores puede ser clasificado en dumping esporádico, dumping depredador o dumping persistente ${ }^{86} . \mathrm{El}$ dumping esporádico o también llamado dumping de liquidación se produce cuando una empresa dispone de un exceso de stock de mercaderías en un mercado extranjero al vender en él a precios inferiores que en el mercado propio. Esto puede derivarse de cambios en condiciones de oferta y demanda que ocasionan un exceso de stock no planificado, surgiendo entonces la necesidad de alterar el precio de venta de productos bajando la línea de precio y cayendo en dumping. El dumping depredador, ocurre cuando se reducen temporalmente los precios de un producto cobrados en el extranjero pero con la finalidad, ya no de reducir inventario sino de sacar del mercado a potenciales o directos competidores. El dumping persistente, se mantiene en el tiempo,

84 OMC. Disponible en http://www.wto.org/spanish/thewto_s/whatis_s/tif_s/agrm8_s.htm

85 Sobre esta materia, vid. Gallegos, J., «Medidas de defensa comercial en el contexto de la OMC. Controversias promovidas en el marco de sus sistema de solución de controversias entre países latinoamericanos», Revista de Derecho, 10:11, Santiago de Chile, 2015, pp. 27-57.

86 Para más detalle y otras diversas formas de clasificación del dumping, vid. CanabELLas, G.; SARAVIA, B., Dumping, subsidios y salvaguardias, op. cit., pp. 84-138. 
obedece a criterios muy propios del país destino de los productos, en donde permite al productor cobrar permanentemente precios más bajos que en los de su propio mercado ${ }^{87}{ }_{-8}^{88}$.

d) Boicot y bloqueo

$\mathrm{Al}$ margen de las BNA ya analizadas, debemos señalar, al menos de manera enunciativa, que existen otro tipo de BNA, que si bien no inciden en aspectos puramente económicos, ciertamente son una forma de distorsión del comercio internacional, por cuanto bloquean u obstruyen el libre movimiento de mercancías y otros factores productivos a nivel internacional. Son BNA movidas más bien por criterios de orden político internacional, sin un objetivo puramente económico, sino más bien de presión internacional. Entre estas BNA podemos encontrar, el «boicot», que consiste en la negativa por parte de un país o de la comunidad internacional actuando concertadamente, de comprar o vender cierto tipo de mercancías a otro país, con el objetivo de presionar a un Estado para que realice concesiones y/o acciones en el ámbito internacional o interno.

También encontramos «el bloqueo», que consiste en una acción política, militar y comercial agresiva, que impide a un país relaciones comerciales con otros países en forma unilateral. Probablemente, el más reconocido de los bloqueos a nivel internacional, sea el bloqueo económico, comercial y financiero, que desde el año 1960, ha sido impuesto por los Estados Unidos a Cuba ${ }^{89}{ }^{90}$, siendo otro ejemplo reciente el bloqueo de Estados Unidos a Venezuela.

En cualquier caso, uno u otro pueden llegar a tener una importante incidencia en el acceso a bienes y servicios de un determinado país, procurando imponer una sanción al Estado, pero repercutiendo sus efectos en sus propios habitantes.

87 Vid. Carbaugh, R., Economía internacional, op. cit., pp. 165-166.

88 Vid, Ossa, F., Economía internacional, aspectos reales, op. cit., p. 250-253.

89 No obstante, transcurridos más de 58 años de bloqueo económico, comercial y financiero impuesto por los Estados Unidos a Cuba, la Asamblea General de Naciones Unidas, con el voto conforme de 191 Estados miembros, y con los votos en contra, únicamente de Estados Unidos e Israel -aprobó el 1 de noviembre de 2017- una resolución que solicita el levantamiento del bloqueo. Pero esta no ha sido la única infructuosa votación encaminada a obtener el levantamiento del bloqueo, a ella se suman, las del 4 de noviembre de 2003, 8 de noviembre de 2005, 28 de octubre de 2014, entre otras tantas más.

90 Sobre esta cuestión, vid. ATIKIAN, J., Cuba under embargo. The macro impact, Smashwords Edition, e-book, pp. 5-8. 
V. RESUltados DE LA POLÍTICA DE LIBRE COMERCIO EN LAS PERSONAS. LOS OBJETIVOS DE DESARROLLO SOSTENIBLE (ODS) DE LA AGENDA 2030

El efecto de la política de libre comercio en las personas, ha quedado condicionado a un resultado indirecto, no como un fin en sí, sino más bien una consecuencia, queremos creer esperada, de la apertura comercial. La equidad en el comercio ha terminado siendo un resultado, no del todo cumplido, entre los sujetos de Derecho internacional que componen la comunidad internacional, léase Estados y Organizaciones internacionales, pero no una consecuencia directa en las personas.

No obstante lo anterior, y quizás de manera más bien excepcional, en la búsqueda de un marco internacional que vincule la equidad del comercio como actividad propia de los Estados, pero en concordancia con las garantías individuales de las personas, encontramos el «derecho al desarrollo» como un ejemplo de incipiente fundamento normativo, en el marco de Naciones Unidas $^{91}$. Cuando nos referimos al «derecho al desarrollo» ${ }^{92}$, entendemos una forma de expresión, al menos en lo jurídico, de una vinculación entre el régimen del comercio internacional, y de forma particular, la desigualdad compensatoria en favor de los países menos desarrollados ${ }^{93}$, con la protección de las garantías individuales y los derechos fundamentales de las personas, entre las cuales ciertamente, encontramos los aspectos económicos. Es así, como en su artículo sexto, la Resolución sobre el derecho al desarrollo señala que:

2. Todos los derechos humanos y las libertades fundamentales son indivisibles e interdependientes; debe darse igual atención y urgente consideración a la aplicación, promoción y protección de los derechos civiles, políticos, económicos, sociales y culturales.

3. Los Estados deben adoptar medidas para eliminar los obstáculos al desarrollo resultantes de la inobservancia de los derechos civiles y políticos, así como de los derechos económicos, sociales y culturales.

91 A pesar de que, como es sabido, las Resoluciones que emanan de la Asamblea General de Naciones Unidas, no tienen efecto vinculante.

92 La Declaración sobre el Derecho al Desarrollo» consta en una Resolución de la Asamblea General de las Naciones Unidas, acordada con fecha 4 de diciembre de 1986. Disponible en http:// www.ohchr.org/SP/ProfessionalInterest/Pages/RightToDevelopment.aspx

93 Casanovas, O.; Rodrigo, A., Compendio de Derecho internacional público, op. cit., p. 491. 
Por tanto, dado su carácter, los Estados tienen el deber de promoción y protección de garantías en materia económica y en consecuencia, el desarrollo económico de los países debe estar en perfecta armonía con los intereses de las personas. Si bien queda claro que sería ingenuo pensar que esta es una regla del todo cumplida, sirve al menos de base para constatar un compromiso ya asumido por la comunidad internacional y que por tanto, no se trata de un afán aislado sino de una promesa formulada por los Estados en la idea de vincular el desarrollo económico directamente con las personas.

Con la llegada del siglo XXI y el cambio de milenio, las organizaciones internacionales comenzaron un importante proceso de redefinición de políticas y objetivos. Fue así, como se desarrollaron una serie de nuevas políticas económicas, comerciales y de otro orden, a través de las cuales se procuraba recoger toda la experiencia que había nutrido las relaciones económicas internacionales durante el siglo anterior, y plasmarlas en nuevos acuerdos que plantearan objetivos acordes a las problemáticas propias del siglo y milenio que comenzaba.

El nuevo siglo nos recibía con supuestos económicos muy distintos a los existentes al inicio del auge organizacional comercial y económico que se dio tras la Segunda Guerra Mundial. Un consistente envejecimiento de la población y junto con ello, un aumento exponencial de la misma ${ }^{94}$, regulares crisis económicas de los países industrializados, incipiente crecimiento de las economías menos adelantadas y junto a lo anterior, una drástica reducción de la pobreza extrema ${ }^{95}$.

Fue así, que tanto la OMC como Naciones Unidas, procurando estar en armonía con los nuevos lineamientos globales, impulsaron una serie de medidas tendentes a las nuevas necesidades y oportunidades de la población.

\section{La Ronda del Milenio de la OMC}

En diciembre de 1999, y tras los activos años 1997 y $1998^{96}$, se cimentaron, en el marco de la OMC, los inicios de la denominada, «Ronda del Mi-

94 Para el año 1950, la estimación de población mundial rondaba los 2.600 millones de habitantes, para el año 1999 la estimación llegaba a los 6.000 millones. Dentro de la presente década la población mundial debería alcanzar la suma de 8.000 millones de personas. Dadas las cifras señaladas, se estima una relación de crecimiento de población para este siglo cercana a los 1.000 millones de habitantes por década. Cfr. ONU. http://www.un.org/es/sections/issues-depth/population/index.html

95 TASSARA, C., Cooperación internacional para el desarrollo: gobierno, economía y sociedad, Universidad de la Salle, Bogotá, 2016, pp. 125-126.

96 En el mes de diciembre de 1996 se había llevado a cabo la Conferencia Ministerial de Singapur, en la cual se definieron una serie de objetivos sectoriales tras el nacimiento de la OMC, que aún 
lenio», ideada inicialmente para llevarse a cabo en la III Reunión Ministerial, en la ciudad de Seattle, Estados Unidos. Sin embargo, y como consecuencia de la actuación de determinados grupos antiglobalización, se vio alterado el trabajo previsto inicialmente, aunque a pesar de ciertos inconvenientes en su realización ${ }^{97}$, permitió fijar al menos, la agenda y materias a abordar para la Ronda del Milenio.

A comienzos del año 2001, en algún lugar lejano de la posible actuación de los movimientos activistas que pudieran frustrar el encuentro, se retomó la actividad de la Ronda del Milenio. El lugar elegido fue la ciudad qatarí de Doha. En noviembre de dicho año, se lleva a cabo la Conferencia Ministerial de Doha, dando inicio a lo que hoy conocemos como Ronda del Desarrollo o también comúnmente denominada «Ronda de Doha para el Desarrollo» ${ }^{98}$. A la mencionada Conferencia Ministerial, le siguieron la de Cancún en 2003, Hong Kong en 2005, Ginebra en 2007, Bali en 2013, Nairobi en el año 2015, y Buenos Aires en 2017, todas ellas con la finalidad de complementar, pero fundamentalmente de poner término a la Ronda de Doha. Sin embargo, cada Conferencia abría nuevos temas y nuevos debates entre países desarrollados y los menos adelantados, que hacían, y hacen hasta ahora, imposible el cierre de la Ronda. A pesar del aparente optimismo por parte de la OMC, al presentar la Ronda de Doha, como una oportuna y necesaria discusión sobre temas del comercio, en la práctica se deduce, transcurridos 17 años, un abierto fracaso en la adopción de acuerdos en materias de comercio discutidas en la propia Ronda, cuyo cierre al día de hoy todavía no se ha producido ${ }^{99}$. Lo lamentable resulta de que uno de sus objetivos centrales, junto con la reducción de obstáculos al comercio, tiene que ver con la mejora de las perspectivas comerciales de las economías en desarrollo. A pesar de que hemos apreciado una mejora

no cumplía dos años. En particular se desarrollaron acuerdos encaminados a la liberalización de las telecomunicaciones, servicios financieros y tecnologías de la información. TAMAMES, R.; Huerta, B., Estructura económica internacional, 21 a ed., op. cit., pp. 173-175.

97 Conocido como «el fiasco de Seattle», dados los inconvenientes sufridos por los grupos antiglobalización y anti OMC. Ibid., p. 175.

98 Este nombre, que tiene el carácter de semioficial, deriva del enfoque que posee la Ronda, que es según la OMC, el mejorar las perspectivas comerciales de los países en desarrollo, Cfr. OMC, https://www.wto.org/spanish/tratop_s/dda_s/dda_s.htm

99 No obstante el optimismo de la vigencia de la Ronda de Doha por parte de la OMC, para algunos la Conferencia Ministerial de Nairobi, Kenia, de 2015 fue una especie de «entierro» de la Ronda dada la imposibilidad de ponerle término después de 14 años de negociaciones. Al respecto, Vid., ORTEGA, A., «El discreto entierro de la Ronda de Doha» Real Instituto Elcano, 2016, Disponible en https://blog.realinstitutoelcano.org/discreto-entierro-la-ronda-doha/ 
en estos aspectos, el no lograr cerrar la Ronda da cuenta de una serie de aspectos pendientes de muy difícil resolución, por una abierta falta de voluntad de economías desarrolladas, como por ejemplo, la defensa de la actividad agrícola llevada a cabo por los países del G-10 ${ }^{100}$.

\section{Los ODS en el borizonte de 2030}

En paralelo a las actuaciones de la OMC, con la llegada del nuevo siglo, las Naciones Unidas decidieron la adopción de un camino de objetivos de largo plazo.

Si para los años noventa, el foco estaba puesto en el desarrollo humano, los derechos humanos y la necesidad de lo que Forcada llama la necesidad del «buen gobierno», en el año 2000, los países forjaron una serie de objetivos en distintos ámbitos, como principios ordenadores de la política de desarrollo en el horizonte del año 2015, naciendo de este modo los «Objetivos de Desarrollo del Milenio» $(\mathrm{ODM})^{101}$. Ocho fueron los objetivos ${ }^{102}$, que tomando como base las cifras del año 1990, se enmarcaron en la Cumbre del Milenio, llevada a efecto el 8 de septiembre del año 2000. El octavo objetivo procuraba el fomento de una asociación mundial entre países ricos y pobres y el respaldo del sector privado $^{103}$. A modo de ejemplo, y en lo que a comercio internacional se refiere, este octavo objetivo dio cuenta de que para el año 2014, el 79\% de las importaciones que provenían de países en desarrollo hacia países desarrollados, fueran admitidas libres de arancel, en comparación con el $65 \%$ existente en el año $2000^{104}$,

${ }^{100}$ Este Grupo de países, de manera permanente, se han resistido a aplicar rebajas a las subvenciones que otorgan a la actividad agrícola. Cfr. UE. «Fichas Técnicas de la Unión Europea», 2018, disponible en http://www.europarl.europa.eu/ftu/pdf/es/FTU_3.2.8.pdf

101 FoRCADA, I., «La cooperación al desarrollo en la Unión Europea y en Naciones Unidas: 2015, el final de la escapada», en Blanc, A. (dir.), Las relaciones entre las Naciones Unidas y la Unión Europea. Seguridad, cooperación y derechos humanos, Madrid, Tecnos, 2013, p.337.

102 Junto a los objetivos propiamente tales, se crearon 18 metas y 48 indicadores. Para el año 2015 terminaron siendo 21 metas y 60 indicadores.

${ }^{103}$ Los otros siete objetivos estaban dirigidos a la erradicación de la pobreza extrema y el hambre; la promoción de la educación primaria universal; la igualdad de género; la reducción de la mortalidad infantil; mejorar la salud materna; la detención del avance del VIH, el paludismo y la tuberculosis y el medio ambiente. TASSARA, C., Cooperación internacional para el desarrollo: gobierno, economía y sociedad, op. cit., pp. 92-93.

${ }^{104}$ Cfr. Naciones Unidas, «Objetivos de Desarrollo del Milenio. Informe de 2015», Disponible en http://www.un.org/es/millenniumgoals/pdf/2015/mdg-report-2015_spanish.pdf 
constatando una efectiva, aunque aún insuficiente, facilitación del comercio de mercancías, desde economías en desarrollo, a economías desarrolladas.

No obstante los esfuerzos, y los incipientes avances obtenidos en el cumplimiento de los ODM, los países procuraron la creación de nuevos objetivos post 2015, que potenciaran las mejoras obtenidas y generaran nuevos desafíos futuros en ámbitos más amplios que los ODM. En este contexto nacen los llamados «Objetivos de Desarrollo Sostenible» (ODS), aprobados por la Asamblea General de las Naciones Unidas, con fecha 25 de septiembre de 2015. Estos ODS consisten en la creación, esta vez, de 17 objetivos, sumando en mayor o menor medida, nuevos objetivos a los ya tratados 15 años atrás. En lo que a comercio y relaciones económicas se trata, los ODS proponen, en particular en su objetivo número 8 , «promover el crecimiento económico sostenido, inclusivo y sostenible, el empleo pleno y productivo y el trabajo decente para todos» ${ }^{105}$. Por otra parte, en su objetivo número 10 se propone, «reducir la desigualdad en y entre los países» ${ }^{106}$. Ambos objetivos resultan del todo relevantes para los fines llevados adelante en el presente trabajo, por cuanto procuran la consolidación de un comercio y una relación de Estados enfocados a las realidades individuales, de la persona como fin, y no como medio para el cumplimiento de objetivos de orden puramente económicos.

Habrá que aguardar los resultados finales, no sólo en los objetivos de orden económico y comercial, sino de manera muy importante en los demás. Ciertamente podemos suponer que llegado el año 2030, los países se procura-

${ }^{105}$ Los últimos datos al año 2017, señalan que tras una leve contracción en el año 2014, la ayuda para el comercio aumentó en un 5,4\% en términos reales, hasta alcanzar los 53.900 millones de dólares, debido a la recuperación de los compromisos contraídos por los países, en materia de infraestructura relacionada con el comercio y al mayor apoyo de la banca y la agricultura. Los compromisos de ayuda para el comercio a los países menos adelantados aumentaron en 4.300 millones de dólares, hasta alcanzar 17.200 millones, para el mismo periodo. En relación a la tasa de crecimiento anual del PIB real per cápita en todo el mundo, fue del 1,6\% entre 2010 y 2015, en comparación con el 0,9\% en el período de 2005 a 2009. En los países menos desarrollados, la tasa de crecimiento per cápita retrocedió, de un 4,6\% entre 2005 y 2009 , a un $2,5 \%$ entre 2010 y 2015. Cfr. Naciones Unidas, «Objetivos de Desarrollo Sostenible. 17 objetivos para transformar nuestro mundo». Disponible en https:// www.un.org/ sustainabledevelopment/es/ economic-growth/

${ }^{106}$ En relación a la reducción de desigualdades, conviene señalar que la exención de derechos y las condiciones de acceso favorable para las exportaciones de los países menos adelantados y los países en desarrollo se han ampliado. Entre 2005 y 2015, la proporción de líneas arancelarias a nivel mundial con exención de derechos para productos originarios de países en desarrollo aumentó del $41 \%$ al $50 \%$; en cambio para los productos originarios de países menos adelantados, esa proporción aumentó desde un 49\% el año 2005, a un 65\% el año 2015. Cfr. Ibid. 
rán nuevos objetivos para tiempos futuros, pero tan relevante como esto es el análisis de resultados, pues sin lugar a dudas parece más fácil la imposición de objetivos que el cumplimiento de sus resultados esperados.

\section{CONSIDERACIONES FINALES}

Hemos identificado y comprendido, la diametral distancia existente entre el concepto de equidad entre los países y la equidad de comercio en las personas. No logramos vislumbrar un objetivo concreto y directo, que en atención al levantamiento de barreras, a la promoción de un comercio leal, o a la liberalización de restricciones, se transformen en una mejora directa al estándar de vida de las personas, como fin último. El libre comercio no promueve la equidad en los individuos, promueve la mejora de posibilidades para el intercambio comercial estatal. El problema por tanto resulta ser, que no siendo el libre comercio, el móvil en donde encontramos el estatuto normativo que promueva de manera directa el bienestar de las personas y la satisfacción de sus necesidades a través del instrumento económico, aquel queda limitado a compromisos de Estados sin carácter vinculante, sin posibilidad de coerción y por tanto, sin obligatoriedad en su cumplimiento.

Indudablemente, tanto la política de libre comercio, por una parte, como los Acuerdos y definiciones de orden económico a nivel global por la otra, han traído mejoras objetivas en los estándares de vida de las personas. El control aparente de las barreras al comercio internacional, su identificación, acotamiento y superación, han tenido como consecuencia un permanente acceso a bienes y servicios por parte de la población mundial, mejoras en las condiciones de trabajo, de movilidad, de crecimiento y de desarrollo económico. Esto resulta incuestionable, pero lo que resulta incuestionable también es que son consecuencia, no un fin en sí mismo.

Sumado a lo anterior, conviene tener en cuenta que las altas fluctuaciones de precios en las actividades primarias y extractivas, que constituyen las principales actividades de las economías menos adelantadas, resultan condenatorias cuando entran en la dinámica de la oferta y la demanda del comercio global. A pesar de que algunos organismos internacionales, particularmente la UNCTAD, han procurado instaurar mecanismos estabilizadores, que equiparen dicho problema, como por ejemplo, en el caso del cacao, trigo, azúcar y aceite, estas medidas resultan absolutamente mínimas e insuficientes. 
Así las cosas, estando en manos de las economías desarrolladas, la elaboración de productos manufacturados, y por otro lado el control de precios de las materias primas, resulta una combinación nociva y dañina para las economías menos adelantadas. Limitarse solamente a proveer producción primaria a la economía global, no será nunca suficiente para mejorar los estándares más básicos de equidad, tanto de naciones, pero fundamentalmente de personas. Ello constituye un llamado de alerta para las economías menos adelantadas, en el sentido que no deben creer que todo está en manos de las grandes potencias o de la labor que las organizaciones internacionales puedan hacer por ellas. Resulta clave el fomento de la industrialización, aun cuando éste sea incipiente, así como del valor agregado a las materias primas y la incorporación de procesos más elaborados a la actividad extractiva, todas ellas mejoras básicas en el proceso de desarrollo económico y comercial de las economías que más lo requieren.

Por su parte, la OMC, ha procurado promover una regulación codificada y predeterminada de los aspectos del comercio, avanzando de forma consistente y creando un verdadero estatuto jurídico mundial del comercio, que los Estados, en mayor o menor medida, han logrado asimilar, implementar y cumplir. Pese a lo anterior, la OMC tiene serios y, de momento, insolubles problemas en la adopción de acuerdos y en la conclusión de avances concretos, constituyendo el fracaso del cierre de la Ronda de Doha la mejor prueba de ello.Ciertamente y a la luz de las conclusiones previas, la tarea no está del todo realizada. Si bien las cifras de superación de pobreza han mejorado consistentemente con el paso de los últimos años, los incrementos casi desproporcionados de natalidad en economías emergentes, la alta volatilidad de los mercados en las economías desarrolladas, con sucesivas crisis e inestabilidades, dan cuenta de que la labor del establecimiento de políticas comerciales que tengan como fin último a la persona son más importantes que nunca. La definición de normas comerciales estatales no parece ser suficiente, pues falta ahora el afán de concluir acuerdos más ambiciosos, así como el cumplimiento cabal de la normativa y de manera especial, la consideración de la persona como fin en sí misma, en la elaboración de políticas comerciales en la perspectiva del año 2030 y aún más allá. 
